\title{
Environment Controls Biomolecule Release from Dynamic Covalent Hydrogels
}

\section{Journal Article}

\section{Author(s):}

Marco-Dufort, Bruno; Willi, Jack; Vielba-Gomez, Felipe; Gatti, Francesco; Tibbitt, Mark (1)

Publication date:

2021-01-11

Permanent link:

https://doi.org/10.3929/ethz-b-000452981

Rights / license:

Creative Commons Attribution-NonCommercial-NoDerivatives 4.0 International

Originally published in:

Biomacromolecules 22(1), https://doi.org/10.1021/acs.biomac.0c00895 


\title{
Environment Controls Biomolecule Release from Dynamic Covalent Hydrogels
}

\author{
Bruno Marco-Dufort, Jack Willi, Felipe Vielba-Gomez, Francesco Gatti, and Mark W. Tibbitt* \\ Cite This: Biomacromolecules 2021, 22, 146-157 \\ Read Online
}

ABSTRACT: Moldable hydrogels composed of dynamic covalent bonds are attractive biomaterials for controlled release, as the dynamic exchange of bonds in these networks enables minimally invasive application via injection. Despite the growing interest in the biomedical application of dynamic covalent hydrogels, there is a lack of fundamental understanding as to how the network design and local environment control the release of biomolecules from these materials. In this work, we fabricated boronicester-based dynamic covalent hydrogels for the encapsulation and in vitro release of a model biologic ( $\beta$-galactosidase). We systematically investigated the role of network properties and of the external environment (temperature and presence of competitive binders) on release from these dynamic covalent hydrogels. We observed that surface erosion (and associated mass

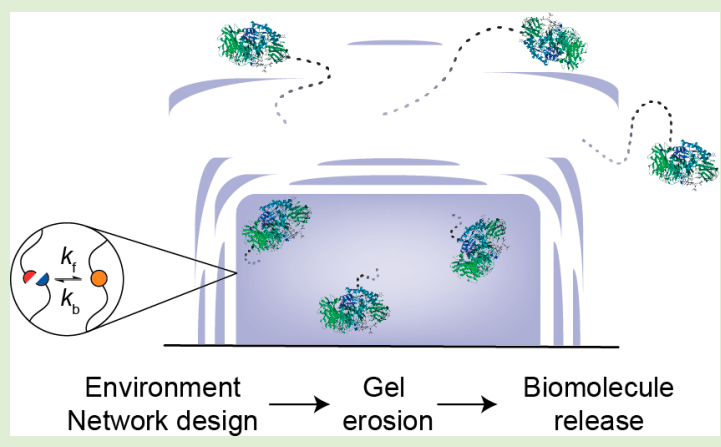
loss) governed biomolecule release. In addition, we developed a statistical model of surface erosion based on the binding equilibria in a boundary layer that described the rates of release. In total, our results will guide the design of dynamic covalent hydrogels as biomaterials for drug delivery applications.

\section{INTRODUCTION}

Medical care relies on pharmaceutical agents to manage disease and restore homeostasis. In recent years, there has been significant progress in the development and approval of new active pharmaceutical ingredients (APIs), with an emphasis on biologics including recombinant growth factors, therapeutic proteins, and nucleic acids. ${ }^{1}$ However, biologics are not inherently beneficial; their efficacy depends on being in the right place in the body, at the right concentration, and at the right time. ${ }^{2}$ Thus, a variety of drug delivery systems (DDS) have been designed to protect and stabilize biologics, control their release, and deliver them to the tissue of interest in vivo. ${ }^{3}$

Hydrogels comprise a particularly versatile class of DDS and have been applied broadly to deliver biologics, including in oncology, immunology, cardiology, and wound healing. ${ }^{4}$ Traditionally, polymeric hydrogels are produced via covalent cross-linking of monomeric or polymeric precursors, forming water-swollen polymer networks. ${ }^{5}$ In this approach, the hydrogel formulation controls the equilibrium swelling ratio and mesh size, which ultimately dictate the release kinetics of encapsulated biomolecules. ${ }^{6,7}$ Responsive hydrogels have been designed to enable reversible changes in swelling or material degradation (bulk or surface erosion) as additional handles to control therapeutic release. ${ }^{4,5}$ For example, degradable hydrogels for the release of biologics have been designed through the inclusion of hydrolytic ester bonds, enzyme-degradable peptide linkers, and photodegradable $o$-nitrobenzylether moieties to enable controlled cleavage of network strands to tailor the mesh size and/or mass loss from the gel and, therefore, release. ${ }^{4,8-12}$ While chemically cross-linked hydrogels are broadly useful, their application can be hindered by the need to implant a formed device or to engineer the fabrication process for in vivo administration.

As an alternative to chemically cross-linked hydrogels, hydrogels formed via physical or supramolecular interactions, including hydrogen bonding, host-guest interactions, peptide or protein self-assembly, and polymer-colloid interactions, have been applied as injectable DDS. ${ }^{13}$ The use of reversible, noncovalent interactions as cross-links in physical or supramolecular hydrogels enables shear-thinning (viscous flow in response to applied stress) and self-healing (gel recovery when the stress is relaxed) properties. ${ }^{14,15}$ Importantly, the shearthinning and self-healing nature of these dynamic materials allows them to be administered locally and in a minimally invasive manner through syringe or catheter injection. ${ }^{16-18}$

More recently, researchers have explored dynamic covalent hydrogels, including through the use of boronic ester crosslinks that form under physiological conditions, as a complementary class of bioinspired macromolecular materials for therapeutic encapsulation and release. ${ }^{19}$ Dynamic covalent

Special Issue: Bioinspired Macromolecular Materials

Received: June 10, 2020

Revised: August 15, 2020

Published: August 19, 2020

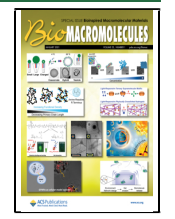


hydrogels integrate properties of both chemically and physically cross-linked networks, enabling the formation of robust yet processable biomaterials. ${ }^{20}$ As the cross-links are under thermodynamic control, the local environment, e.g., $T, \mathrm{pH}$, and concentration of competitive binders, dictates the fraction of bound cross-links, which can vary in space and time. These properties have been applied to engineer boronic-ester-based hydrogels for glucose responsive delivery of insulin and other biologics. ${ }^{19,21}$ As the field further develops this class of materials, a robust understanding of how network properties and the local chemical environment control release from dynamic covalent hydrogels is needed. This is critical as the release behavior from reversibly cross-linked materials can be more complex than from permanently cross-linked hydrogels; ${ }^{22}$ dynamic covalent hydrogels erode on experimental time scales and their swelling ratio and mesh size cannot be calculated using classic equilibrium theories. Therefore, a robust understanding of how the local chemical environment controls release from hydrogels with reversible cross-links is needed to improve the design of more precise medical therapies.

In this work, we characterize the encapsulation and in vitro release of a model biologic ( $\beta$-galactosidase) from boronicester-based dynamic covalent hydrogels. We investigate the role of network properties and environmental conditions on biomolecule release from this reversible hydrogel platform. We highlight the importance of surface erosion (and associated mass loss) in controlling the release behavior from dynamic covalent hydrogels. Finally, we introduce a statistical model that describes how the local chemical environment dictates the rates of surface erosion, and associated release, in these networks. These findings advance our understanding of how to exploit dynamic covalent chemistry for the design of controlled release technologies.

\section{EXPERIMENTAL SECTION}

Materials. Chemicals. 4-Arm PEG- $\mathrm{NH}_{2} \mathrm{HCl}\left(M_{\mathrm{n}}=10000 \mathrm{~g}\right.$ $\mathrm{mol}^{-1}$ ) and 8-Arm PEG- $\mathrm{NH}_{2} \mathrm{HCl}$ (tripentaerythritol core; $M_{\mathrm{n}} \stackrel{g}{=}$ $10000 \mathrm{~g} \mathrm{~mol}^{-1}$ ) were purchased from JenKem Technology USA. Anhydrous methanol (MeOH), dichloromethane (DCM), 2formylphenylboronic acid (2-FPBA), triethylamine, sodium borohydride $\left(\mathrm{NaBH}_{4}\right)$, D- $(+)$-gluconic acid $\delta$-lactone (gluconolactone; GL), 2,2-dihydroxyindane-1,3-dione (ninhydrin), hydrochloric acid ( $\mathrm{HCl})$, sodium hydroxide $(\mathrm{NaOH})$, potassium hydroxide $(\mathrm{KOH})$, dimethylammonium chloride, anhydrous magnesium sulfate $\left(\mathrm{MgSO}_{4}\right)$, sodium sulfate $\left(\mathrm{Na}_{2} \mathrm{SO}_{4}\right)$, sodium bicarbonate $\left(\mathrm{NaHCO}_{3}\right)$, deuterated water $\left(\mathrm{D}_{2} \mathrm{O}\right)$, deuterated methanol $\left(\mathrm{CD}_{3} \mathrm{OD}\right)$, sodium dihydrogen phosphate (monobasic; $\mathrm{NaH}_{2} \mathrm{PO}_{4}$ ), sodium hydrogen phosphate (dibasic; $\left.\mathrm{Na}_{2} \mathrm{HPO}_{4}\right), \beta$-galactosidase from Aspergillus oryzae ( $\beta$-gal), ortho-nitrophenyl $\beta$-D-galactopyranoside (ONPG), anti-mouse IgGAtto 594 (IgG-Atto 594), Alizarin Red S (ARS), D-(-)-fructose (fructose), D-mannitol (mannitol), D-(+)-glucose (glucose), and rhodamine B were purchased from Sigma-Aldrich. Regenerated cellulose dialysis tubing (MWCO $1 \mathrm{kDa}$ ) was purchased from Repligen.

Analytical Techniques. NMR. ${ }^{1} \mathrm{H}$ 1D NMR spectra were acquired on a Bruker Avance III 400 (Bruker BioSpin GmbH). The residual undeuterated solvent peak $\left(4.70 \mathrm{ppm}\right.$ for $\mathrm{D}_{2} \mathrm{O}$ and $3.34 \mathrm{ppm}$ for $\mathrm{CD}_{3} \mathrm{OD}$ ) was used for reference. The relative integration is reported as number of protons $(\mathrm{H})$ and the following abbreviations were used to denote multiplicities: $\mathrm{s}=$ singlet, $\mathrm{d}=$ doublet, $\mathrm{t}=$ triplet, $\mathrm{m}=$ multiplet, and $\mathrm{br}=$ broad.

pH Meter. $\mathrm{pH}$ was measured using a calibrated $\mathrm{pH} 1100 \mathrm{~L}$ precision $\mathrm{pH}$ meter (VWR International $\mathrm{GmbH}$ ).

Plate Reader. Absorbance and fluorescence measurements were acquired with a Hidex Sense Microplate Reader (Hidex; Turku,
Finland). Absorbance was measured at $420 \mathrm{~nm}$, using clear 96-well tissue culture plates (flat bottom). Fluorescence was measured using black 96-well plates (Microfluor 1; flat bottom). For the fluorescence measurements of the PBA-ARS adduct, samples were excited at 460 $\mathrm{nm}$ and emission was measured at $575 \mathrm{~nm}$. For the fluorescence measurements of IgG-Atto 594, samples were excited at $590 \mathrm{~nm}$ and emission was measured at $615 \mathrm{~nm}$.

Rheometer. Rheometric characterization was performed using a strain-controlled shear rheometer (MCR 502; Anton-Paar; Zofingen, Switzerland) equipped with a Peltier stage to control the temperature $\left(T=5-50^{\circ} \mathrm{C}\right)$. Silicone oil was applied to the samples to prevent drying and all experiments were performed at $25{ }^{\circ} \mathrm{C}$ unless stated otherwise. All measurements were performed using a $20 \mathrm{~mm}$ parallel plate geometry with a gap of $0.5 \mathrm{~mm}$. Motor adjustments were performed prior to each experiment. The samples were prepared at least $2 \mathrm{~h}$ before each experiment to allow for complete gelation. The samples were loaded by placing them directly on the Peltier plate and lowering the geometry to the desired gap. After loading, the samples were equilibrated to the set temperature for at least $15 \mathrm{~min}(\gamma=0.1 \%$; $\left.\omega=1 \mathrm{rad} \mathrm{s}^{-1}\right)$. Frequency sweep experiments (FS) were performed at $\gamma=1 \%$ (within the linear viscoelastic regime as determined from strain sweep experiments) for $\omega=100-0.01 \mathrm{rad} \mathrm{s}^{-1}$.

Methods. Synthesis. 1D ${ }^{1} \mathrm{H}$ NMR spectra for the synthesized compounds can be found in Supporting Information SI 1.

The synthesis of 4-arm PEG-APBA was performed according to a published procedure with some modifications. ${ }^{19}$ 4-Arm PEG$\mathrm{NH}_{2} \mathrm{HCl}\left(2.0 \mathrm{~g}, 0.2 \mathrm{mmol} ; M_{\mathrm{n}}=10000 \mathrm{~g} \mathrm{~mol}^{-1}\right)$ was dissolved in anhydrous $\mathrm{MeOH}(10 \mathrm{~mL})$ in a round-bottom flask equipped with a stir bar. Triethylamine $(0.5 \mathrm{~mL}, 3.6 \mathrm{mmol})$ and 2 -formylphenylboronic acid (180 mg, $1.2 \mathrm{mmol}$ ) were added to the reaction, and it was left to proceed for $72 \mathrm{~h}$ at room temperature under argon gas. The reaction was then cooled on ice to $4{ }^{\circ} \mathrm{C}$, and $\mathrm{NaBH}_{4}(90 \mathrm{mg}, 2.4$ $\mathrm{mmol}$ ) was added portion wise. The reaction was left to proceed for $12 \mathrm{~h}$ at room temperature, after removing the ice bath. $\mathrm{MeOH}$ was evaporated and the remaining product was dissolved in DI water. The $\mathrm{pH}$ of the aqueous solution was balanced to 7 (using $1 \mathrm{M} \mathrm{HCl}$ ), dialyzed against DI water for $72 \mathrm{~h}(1 \mathrm{kDa}$ MWCO $)$, filtered $(0.2 \mu \mathrm{m})$, and then lyophilized to yield a white powder. ${ }^{1} \mathrm{H}\left(400 \mathrm{MHz}, \mathrm{D}_{2} \mathrm{O}\right): \delta$ 7.4-7.1 (m, $16 \mathrm{H}), 4.0(\mathrm{~s}, 8 \mathrm{H}), 3.6(\mathrm{~m}, 892 \mathrm{H}), 3.0(\mathrm{t}, 8 \mathrm{H})$. The degree of functionalization determined from ${ }^{1} \mathrm{H}$ NMR was $\approx 85 \%$ (theoretical $M_{\mathrm{n}}=10480 \mathrm{~g} \mathrm{~mol}^{-1}$ ).

The synthesis of 4-arm PEG-GL was performed according to a published procedure with some modifications. ${ }^{19}$ 4-Arm PEG$\mathrm{NH}_{2} \mathrm{HCl}\left(2.0 \mathrm{~g}, 0.2 \mathrm{mmol} ; M_{\mathrm{n}}=10000 \mathrm{~g} \mathrm{~mol}^{-1}\right)$ was dissolved in anhydrous $\mathrm{MeOH}(50 \mathrm{~mL})$ in a round-bottom flask equipped with a stir bar, followed by the addition of triethylamine $(1.0 \mathrm{~mL}, 7.2 \mathrm{mmol})$ and D-(+)-gluconic acid $\delta$-lactone $(285 \mathrm{mg}, 1.6 \mathrm{mmol})$. The reaction was allowed to proceed for $72 \mathrm{~h}$ at room temperature. At this point, the extent of the reaction was monitored by performing a ninhydrin test, to detect the presence of free amines (blue $=$ unreacted amines still present; yellow/colorless = amines successfully coupled). If free amines persisted, additional triethylamine $(1.0 \mathrm{~mL}, 7.2 \mathrm{mmol})$ and D(+)-gluconic acid $\delta$-lactone $(285 \mathrm{mg}, 1.6 \mathrm{mmol})$ were added, and the reaction was left to proceed for another $24-72 \mathrm{~h}$ at room temperature. After evaporation of the $\mathrm{MeOH}$, the remaining product was dissolved in DI water. The $\mathrm{pH}$ of the aqueous solution was balanced to 7 (using $1 \mathrm{M} \mathrm{NaOH}$ ), dialyzed against DI water for $72 \mathrm{~h}$ ( $1 \mathrm{kDa}$ MWCO), filtered $(0.2 \mu \mathrm{m})$, and then lyophilized to yield a white powder. ${ }^{1} \mathrm{H}\left(400 \mathrm{MHz}, \mathrm{D}_{2} \mathrm{O}\right): \delta 4.3(\mathrm{~d}, 4 \mathrm{H}), 4.0(\mathrm{t}, 4 \mathrm{H}), 3.6$ $(\mathrm{m}, 924 \mathrm{H})$. The degree of functionalization determined from ${ }^{1} \mathrm{H}$ NMR was $\approx 85 \%$ (theoretical $M_{\mathrm{n}}=10713 \mathrm{~g} \mathrm{~mol}^{-1}$ ).

The syntheses of 8-arm PEG-APBA and 8-arm PEG-GL were performed according to the same procedures as above, but the amounts of each reagent added were adjusted to account for the higher stoichiometry of $\mathrm{NH}_{2}$ in the 8-arm PEG. The degree of functionalization determined from ${ }^{1} \mathrm{H}$ NMR was $\approx 85 \%$ for 8 -arm PEG-APBA (theoretical $M_{\mathrm{n}}=11094 \mathrm{~g} \mathrm{~mol}^{-1}$ ) and $\approx 85 \%$ for 8 -arm PEG-GL (theoretical $M_{\mathrm{n}}=11447 \mathrm{~g} \mathrm{~mol}^{-1}$ ).

The synthesis of 2-((dimethylamino)methyl)phenylboronic acid (DAPBA) was performed according to a published procedure with 
some modifications. ${ }^{23}$ Dimethylammonium chloride (3.25 g, 40 mmol) was dissolved in anhydrous $\mathrm{MeOH}(30 \mathrm{~mL})$ in a $250 \mathrm{~mL}$ round-bottom flask equipped with a stir bar, followed by the addition of $\mathrm{KOH}(2.25 \mathrm{~g}, 40 \mathrm{mmol})$. After the $\mathrm{KOH}$ pellets were completely dissolved, anhydrous $\mathrm{MgSO}_{4}$ (15 g) was added to scavenge water. Next, 2-formylphenylboronic acid $(3.0 \mathrm{~g}, 20 \mathrm{mmol})$ was added and the solution was stirred at room temperature for $2 \mathrm{~h}$. Afterward, the slurry was cooled on ice to $4{ }^{\circ} \mathrm{C}$, and $\mathrm{NaBH}_{4}(1.2 \mathrm{~g}, 30 \mathrm{mmol})$ was added portion wise. The reaction was left to proceed for $12 \mathrm{~h}$ at room temperature, after removing the ice bath. After filtering the slurry to remove the salts, the remaining $\mathrm{MeOH}$ was evaporated. DI water (30 $\mathrm{mL}$ ) and saturated $\mathrm{NaHCO}_{3}(30 \mathrm{~mL})$ were added to the solution, and the product was extracted with DCM $(3 \times 300 \mathrm{~mL})$. The DCM phases were combined, dried over $\mathrm{Na}_{2} \mathrm{SO}_{4}$, filtered, and the DCM was evaporated to yield a white powder $\left(\approx 60 \%\right.$ yield; $\left.179.03 \mathrm{~g} \mathrm{~mol}^{-1}\right){ }^{1} \mathrm{H}$ $\left(400 \mathrm{MHz}, \mathrm{CD}_{3} \mathrm{OD}\right): \delta 7.5-7.1(\mathrm{~m}, 4 \mathrm{H}), 4.0(\mathrm{~s}, 2 \mathrm{H}), 2.6(\mathrm{~s}, 6 \mathrm{H})$.

Formation of Hydrogels. Aqueous stock solutions of the networkforming precursors, phenylboronic acid-containing (PEG-APBA) and diol-containing (PEG-GL), were prepared in $0.1 \mathrm{M}$ phosphate buffer (0.086 $\mathrm{M}$ dibasic and $0.014 \mathrm{M}$ monobasic; $\mathrm{pH}$ adjusted to 7.5 using 1 $\mathrm{M} \mathrm{HCl}$ or $1 \mathrm{M} \mathrm{NaOH}$ ). To fabricate the gels, equivalent volumes of the two stock solutions were combined and gelation occurred within 10 s. All samples were formed at least $2 \mathrm{~h}$ before use, to ensure complete gelation. Unless otherwise stated, 4-arm PEG APBA/GL was used and the final concentration of polymer in the networks was $10 \mathrm{wt} / \mathrm{wt} \%$ PEG.

Mass Loss Experiments. Gels were formed at the bottom of $2 \mathrm{~mL}$ reaction tubes (\#623201; Greiner Bio-One). After centrifugation (1 $\mathrm{min}$ ), gels were molded into a conical shape. The total volume of the gels was $40 \mu \mathrm{L}$. To release the samples, the gels in the tube were immersed in phosphate buffer $(\mathrm{pH} 7.5 ; 2.0 \mathrm{~mL})$ at 4,25 , and $37^{\circ} \mathrm{C}$. At defined times, the supernatant was removed and the tubes, with the remaining gel inside, were lyophilized. The mass of the empty tubes, before gel formation, was subtracted from the mass of the tubes containing the dried polymer, to quantify the fractional mass loss of polymer as a function of time, $M(t) / M_{0}$, where $M(t)$ is the cumulative mass lost at time $t$ and $M_{0}$ is the total mass of the initial gel.

$\beta$-Gal Release Experiments. Gels were loaded with $\beta$-galactosidase ( $\beta$-gal) by mixing $10 \mu \mathrm{L}$ of aqueous $\beta$-gal stock solution $\left(40 \mathrm{mg} \mathrm{mL}^{-1}\right.$ $\beta$-gal; $0.1 \mathrm{M}$ phosphate, $\mathrm{pH} 7.5$ ) with $15 \mu \mathrm{L}$ of PEG-GL and $15 \mu \mathrm{L}$ of PEG-APBA stock solutions. The concentration of the PEG stock solutions was adjusted to yield the desired final polymer content (5, 10 , or $20 \mathrm{wt} / \mathrm{wt} \%$ ). For example, $13.33 \mathrm{wt} / \mathrm{wt} \%$ PEG stocks were required to yield a final concentration of $10 \mathrm{wt} / \mathrm{wt} \%$ PEG. As above, conical-shaped gels were formed at the bottom of $2 \mathrm{~mL}$ reaction tubes after centrifugation $(1 \mathrm{~min})$. The total volume of the gels was $40 \mu \mathrm{L}$. To release the $\beta$-gal, the gels in the tube were immersed in phosphate buffer $(\mathrm{pH} 7.5 ; 2.0 \mathrm{~mL})$ at 4,25 , and $37{ }^{\circ} \mathrm{C}$. In some experiments, a sugar (fructose, mannitol, or glucose), at a range of concentrations $\left(1-170 \mathrm{mg} \mathrm{mL}^{-1} ; 0.0055-1.1 \mathrm{M}\right)$, was included in the release buffer formulation. In all cases, the supernatant was assessed at defined time points for $\beta$-gal activity by taking small test samples $(50 \mu \mathrm{L})$ for further analysis (see below) and the removed supernatant was replaced with fresh release buffer $(50 \mu \mathrm{L})$.

To select the concentration of $\beta$-gal in the gels, we characterized the release kinetics for three different loadings of $\beta$-gal in the gels (1, 2.5 , and $10 \mathrm{mg} \mathrm{mL}^{-1}$; SI 2). While the amount of enzyme in the gels slightly affected release rates when no releasing sugar was present, the effect of $\beta$-gal loading on the release was not a significant factor for erosion-based release from the gels (Figure S6). Therefore, $10 \mathrm{mg}$ $\mathrm{mL}^{-1}$ was selected as the final concentration of $\beta$-gal in the gels for all conditions.

Characterization of $\beta$-Galactosidase Activity. The encapsulated $\beta$-gal was released in its active form; therefore, $\beta$-gal activity in the supernatant was used to quantify the fractional release of protein as a function of time, $\beta$-gal $(t) / \beta$-gal ${ }_{0}$ via colorimetry. $\beta$-Gal activity was measured using ortho-nitrophenyl- $\beta$-galactopyranoside (ONPG) according to the manufacturer's protocol (Sigma-Aldrich). Briefly, room-temperature ONPG (16 mM in $0.1 \mathrm{M}$ phosphate buffer; $\mathrm{pH}$ adjusted to 7.5 ) was mixed 2:1 with the $\beta$-gal test solution in a 96-well plate (ONPG: $\beta$-gal test solution; $100 \mu \mathrm{L}: 50 \mu \mathrm{L}$ ). $\beta$-Gal catalyzes the hydrolysis of ONPG to release ortho-nitrophenol, a chromogenic substrate with maximal absorbance at $420 \mathrm{~nm}$. Absorbance at $420 \mathrm{~nm}$ was measured every $60 \mathrm{~s}$ for $10 \mathrm{~min}$, and the mean slope of the resultant curve was recorded. To quantify $\beta$-gal $(t) / \beta$-gal ${ }_{0}$, the mean slope of the $\beta$-gal test solution at each time point was compared to that of freshly prepared $\beta$-gal solution $(200 \mu \mathrm{g} / \mathrm{mL}) . \beta$-gal $(t)$ is the cumulative amount of active $\beta$-gal released at time, $t$, and $\beta$-gal $l_{0}$ is the total amount of $\beta$-gal loaded into the gel initially.

IgG-Atto 594 Release Experiments. Gels were loaded with IgGAtto 594 (IgG) by mixing $10 \mu \mathrm{L}$ of aqueous IgG stock solution $(1 \mathrm{mg}$ $\mathrm{mL}^{-1} \mathrm{IgG}$; undiluted) with $15 \mu \mathrm{L}$ of PEG-GL and $15 \mu \mathrm{L}$ of PEGAPBA stock solutions. The concentration of the PEG stock solutions was adjusted to yield the desired final polymer content. Here, 13.33 wt/wt \% PEG stocks were used to yield a final concentration of 10 $\mathrm{wt} / \mathrm{wt} \% \mathrm{PEG}$. As for the $\beta$-gal release experiments, conical-shaped gels were formed at the bottom of $2 \mathrm{~mL}$ reaction tubes after centrifugation $(1 \mathrm{~min})$. The total volume of the gels was $40 \mu \mathrm{L}$ and the final concentration of IgG in the gels was $0.25 \mathrm{mg} \mathrm{mL}^{-1}$. To release the $\mathrm{IgG}$, the gels in the tube were immersed in phosphate buffer $(\mathrm{pH} 7.5 ; 2.0 \mathrm{~mL})$ at $25{ }^{\circ} \mathrm{C}$. In some experiments, mannitol $\left(100 \mathrm{mg} \mathrm{mL}^{-1}\right)$ was included in the release buffer formulation. In both cases, the concentration IgG in the supernatant was assessed at defined time points by taking small test samples $(100 \mu \mathrm{L})$ and measuring the fluorescence of the $\operatorname{IgG}$ using the plate reader $\left(\lambda_{\text {excitation }}\right.$ $=590 \mathrm{~nm}$ and $\left.\lambda_{\text {emission }}=615 \mathrm{~nm}\right)$. The removed supernatant was replaced with fresh release buffer $(100 \mu \mathrm{L})$.

$K_{\text {eq,D }}$ Measurements. The equilibrium binding constant $\left(K_{\text {eq, } D}\right)$ between phenylboronic acid (PBA) derivatives and various sugars was determined following previously published methods. ${ }^{23,24}$ In brief, a fluorescence-based competitive displacement assay was used involving three components: a PBA derivative (2-FPBA, DAPBA, or PEGAPBA), a diol (fructose, mannitol, or glucose), and Alizarin Red $S$ (ARS; a diol-containing fluorescent reporter). All the stock solutions were prepared in $0.1 \mathrm{M}$ phosphate buffer adjusted to $\mathrm{pH} 7.5$ and at $T$ $=25^{\circ} \mathrm{C}$. The PBA-ARS equilibrium $\left(K_{\mathrm{ARS}}\right)$ was first determined by titrating PBA (initially $2 \mathrm{mM})$ into ARS $(0.009 \mathrm{mM})$ and measuring the fluorescence increase due to the formation of the PBA-ARS adduct $\left(\lambda_{\text {excitation }}=460 \mathrm{~nm}\right.$ and $\left.\lambda_{\text {emission }}=575 \mathrm{~nm}\right)$. From there, $K_{\text {eq, } \mathrm{D}}$ was determined by titrating the diol (with the initial concentration depending on the strength of the PBA-diol interaction) into the PBA/ ARS solution and monitoring the decrease in fluorescence caused by the competitive displacement of the ARS by the diol. Calculation details and representative titration curves for $K_{\mathrm{ARS}}$ and $K_{\text {eq,D }}$ determination can be found in SI 3. For 2-FPBA, we found that $K_{\mathrm{eq}, \mathrm{D}}=[330,270,15]$ for fructose, mannitol, and glucose, respectively. For DAPBA, we found that $K_{\mathrm{eq}, \mathrm{D}}=[90,85, \mathrm{n} / \mathrm{d}]$ for fructose, mannitol, and glucose, respectively $\left(K_{\mathrm{eq}, \mathrm{D}}\right.$ of DAPBA and glucose was too small to be determined). For PEG-APBA, we found that $K_{\mathrm{eq}, \mathrm{D}}=[40,20,3]$ for fructose, mannitol, and glucose, respectively.

$K_{\text {eq }}$ Measurements. The equilibrium constant $\left(K_{\mathrm{eq}}\right)$ between the components that comprise the network (PEG-APBA and PEG-GL) was determined through rheometric analysis. ${ }^{25}$ The plateau modulus of the gel, $G_{\mathrm{p}}$, at different polymer concentrations (wt/wt \%) was fit to a modified version of the classic phantom network model for ideal networks (4-arm PEG-APBA/GL; pH 7.5, $25^{\circ} \mathrm{C} ; \gamma=1 \%$; SI 4). This model accounts for the modulation of formed cross-links based on $K_{\mathrm{eq}}$ and the concentration of reactive groups. ${ }^{26,27}$ From the fit of $G_{\mathrm{p}}$ as a function of wt/wt \%, a single value for the reaction Gibbs free energy, $\Delta G_{\mathrm{r}}^{0}$, was determined, which was used to calculate $K_{\mathrm{eq}}$ at each temperature according to

$$
\Delta G_{\mathrm{r}}^{\circ}=-R T \ln K_{\mathrm{eq}}
$$

We found that $K_{\text {eq }}=[195,240,370]$ for $T=37,25$, and $4{ }^{\circ} \mathrm{C}$, respectively.

Model of Erosion in Dynamic Covalent Networks. Model Development. We developed a statistical model of surface erosion in dynamic covalent networks based on the binding equilibrium between 


\section{a) Network components}

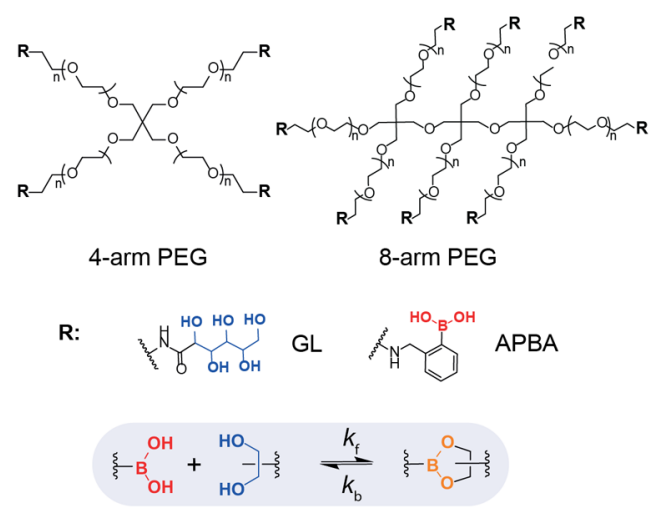

c) Dynamic equilibrium

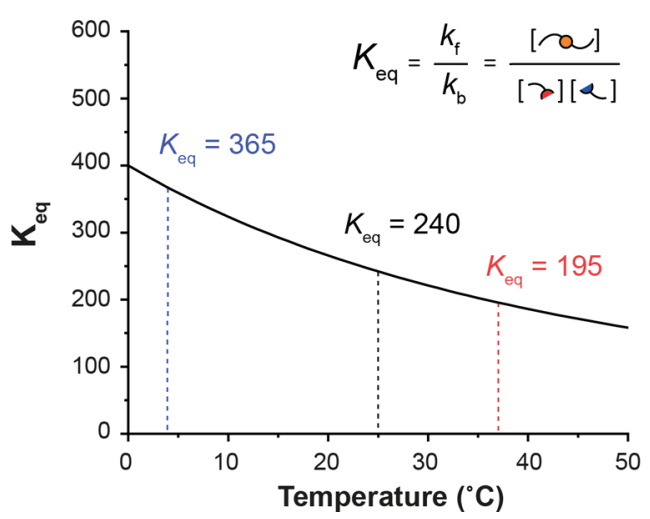

b) Ideal behavior

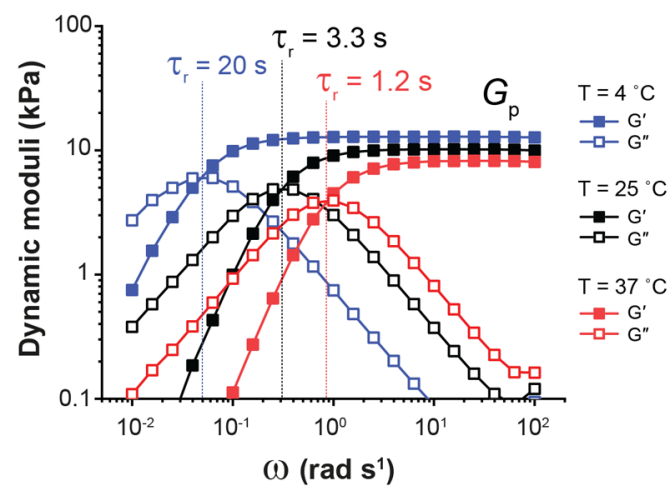

d) Release in reversible networks

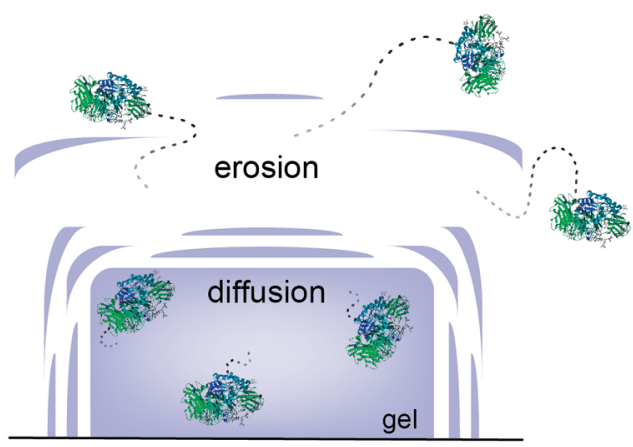

Figure 1. Network dynamics and binding equilibrium control release in dynamic covalent networks. (a) Ideal boronic-ester-based hydrogels were formed via reversible covalent bonding between boronic acid (red) and diol (blue), forming dynamic boronic esters (orange). 4-Arm and 8-arm poly(ethylene glycol) (PEG) macromers (10000 $\mathrm{g} \mathrm{mol}^{-1}$ ) were end-functionalized with either a boronic acid (APBA) or with a diol (GL). (b) Boronic-ester-based networks exhibited canonical Maxwell model behavior for ideal reversible networks, modeled as a spring and a dashpot in series. The relaxation time, $\tau_{\mathrm{r}}$, characterized the dynamics of network strand rearrangement (4-arm PEG-APBA/GL, $10 \mathrm{wt} / \mathrm{wt} \% ; \mathrm{pH} 7.5 ; \gamma=1 \%$ ). (c) The plateau modulus, $G_{\mathrm{p}}$, of the gels at different polymer concentrations was used to calculate the equilibrium constant, $K_{\text {eq }}$, of the boronic ester junctions (4-arm PEG-APBA/GL; $\mathrm{pH} 7.5 ; \gamma=1 \%$ ). (d) Release of biomolecules in reversible hydrogels occurs through a combination of diffusion and surface erosion of the network.

network forming species, a mean-field description of network connectivity, and free polymer chain diffusion. ${ }^{28,29}$ To compare gel erosion with protein diffusion, we calculated the effective time scales of erosion and diffusion in the gels. Based on studies for biomolecules in $10 \mathrm{wt} / \mathrm{wt} \%$ PEG-based hydrogsl, we assumed a $\beta$-gal diffusion coefficient, $D_{\beta \mathrm{gal}}$ of $4.0 \mu \mathrm{m}^{2} \mathrm{~s}^{-1}$. ${ }^{30}$ The gels were formed in the bottom of $2.0 \mathrm{~mL}$ reaction tubes as truncated cones with a height, $h$, of $2.68 \mathrm{~mm}$ for $40 \mu \mathrm{L}$ gels. We defined the time scale for diffusion as $\tau_{\mathrm{D}}=h^{2} / 4 D_{\beta \text { gal }} \approx 125 \mathrm{~h}$ and the time scale for erosion as $\tau_{\mathrm{E}}=h / 2 B$, where $B$ is the erosion rate $\left(\mathrm{mm} \mathrm{h}^{-1}\right)$. Following the approach of Lee, we used a dimensionless parameter to estimate the ratio of the kinetics of erosion to diffusion in the system as $\alpha=B h / 2 D_{\beta \mathrm{gal} .}{ }^{31}$ As the rate of $\beta$-gal diffusion was slow compared to the observed rates of erosion in the majority of samples tested here $(\alpha>10)$, we assumed that $\beta$-gal release occurred through erosion-based mass loss from the gel.

Next, we defined a characteristic time scale for the system as the relaxation time, $\tau_{\mathrm{r}}$, of the hydrogel, measured by shear rheometry. The network structure of the gel was treated as static for $t<\tau_{\mathrm{r}}$, and the network was allowed to rearrange at $t=\tau_{\mathrm{r}}$. We focused our analysis of erosion on a boundary layer at the interface of the surface of the gel and the release buffer. ${ }^{29,32}$ We defined a critical length scale of the boundary layer as the distance that a free (nonassociated) polymer chain can diffuse during the relaxation time, $l_{\mathrm{c}}=\left(D_{\mathrm{p}} \tau_{\mathrm{r}}\right)^{1 / 2}$, where $D_{\mathrm{p}}$ is the diffusion coefficient of a nonassociated polymer chain. We assumed that $D_{\mathrm{p}}=15 \mu \mathrm{m}^{2} \mathrm{~s}^{-1}$ in the boundary layer during the relaxation time, as we treated free polymer chains as nonassociating polymers for $t<\tau_{\mathrm{r}}{ }^{33,34}$

Within this boundary layer, we applied a mean-field approach to calculate the fraction of bound boronic esters, $p$, based on the binding equilibrium of the network forming species. In the absence of a competitive diol, ${ }^{27}$

$$
p=\left(1+\frac{1}{c_{\mathrm{gel}} f K_{\mathrm{eq}}}\right)-\left[\left(1+\frac{1}{c_{\mathrm{ge} e} f K_{\mathrm{eq}}}\right)^{2}-1\right]^{1 / 2}
$$

where $c_{\text {gel }}$ is the concentration of the network in the boundary layer, $f$ is the functionality of the network forming polymers, and $K_{\mathrm{eq}}$ is the equilibrium constant for the boronic acid and diol that comprise the network. In the presence of a competitive diol, $p$ was determined by solving the following expression that describes competitive binding for $p:^{35}$

$$
[\text { diol }]_{\mathrm{eff}}=\left(\frac{K_{\mathrm{eq}} p}{1-p}+K_{\mathrm{eq}, \mathrm{D}}\right)\left[\frac{c_{\mathrm{gel}}(1-p)}{K_{\mathrm{eq}} p}-1-\frac{c_{\mathrm{gel}}(1-p)}{K_{\mathrm{eq}}}\right]
$$

where $[\mathrm{diol}]_{\mathrm{eff}}$ is the effective concentration of the competitive diol in the boundary layer and $K_{\mathrm{eq}, \mathrm{D}}$ is the equilibrium binding constant 
between the boronic acid and the competitive diol. From $p$, we calculated the sol fraction in the boundary layer, $P_{\text {sol }}$. When $p$ drops below $p_{\mathcal{c}}$, the critical percolation threshold, the network will pass through a reverse gel point locally and the boundary layer will dissolve completely $\left(P_{\text {sol }}=1\right) .^{28}$ Based on equal stoichiometry of the boronic acid and diol in our networks, $p_{\mathrm{c}}=\frac{1}{(f-1)}, p_{\mathrm{c}}=0.33$ or 0.14 for $f=4$ or 8 , respectively. ${ }^{36-38}$ For $p \geq p_{\mathcal{c}}$, we calculated $P_{\text {sol }}$ through the following recursive relation

$$
P_{\text {sol }}^{1 / f}=(1-p)+p P_{\text {sol }}^{(f-1) / f}
$$

given the functionality of the network, $f$.

We then defined an erosion rate $B=l_{c} / t_{c}$, where $t_{c}$ is the critical time required to dissolve this boundary layer. For the cases where the boundary layer dissolved $\left(P_{\text {sol }}=1 ; p \leq p_{\mathrm{c}}\right)$ within $\tau_{\mathrm{r}}$, we equated $t_{\mathrm{c}}$ with $\tau_{\mathrm{r}}$ and $B=\left(D_{\mathrm{p}} / \tau_{\mathrm{r}}\right)^{1 / 2}$. When the boundary layer did not dissolve within $\tau_{\mathrm{r}}$, we estimated the critical time for the boundary layer to dissolve, $t_{\mathcal{c}}$ by iterating forward in time steps of $\tau_{\mathrm{r}}$ until $P_{\mathrm{sol}}=1$ ( $p \leq$ $p_{c}$ ) at time step $j$. We calculated $j$ by tracking the behavior of the boundary layer during the iterative time steps of $\tau_{\mathrm{r}}$. Within each time step, the network structure of the gel was treated as static with a given fraction of bound esters, $p$, which depended on eq 2 or 3 . In the iterative steps, $c_{\text {gel }}=c_{\text {gel }}{ }^{i}$, where $c_{\text {gel }}{ }^{i}$ is the polymer concentration in the boundary layer in the $i$ th time step. Based on the assumptions above (free chains are treated as nonassociating polymers and the length scale of the boundary layer is defined by diffusion of free chains), the entire sol fraction in the boundary layer was removed from the gel during each time step. If $P_{\text {sol }}<1\left(p>p_{c}\right)$, we then evaluated the next, $(i+1)$ th, time step of $\tau_{\mathrm{r}}$ in the boundary layer. As the diffusion coefficient for associating polymers in associating polymer networks is orders of magnitude smaller than nonassociating polymers, we treated the boundary layer as an isolated system that did not exchange mass with subsequent layers. ${ }^{33,34}$ The boundary layer was allowed to rearrange with a new gel concentration, $c_{\text {gel }}{ }^{i+1}=c_{\text {gel }}{ }^{i}\left(1-P_{\text {sol }}\right)$. We assumed that $P_{\text {sol }}$ was composed equally of PEG-APBA and PEG-GL. We then calculated $p$ and $P_{\text {sol }}$ for the $(i+1)$ th time step. The process was repeatedly iteratively until $P_{\text {sol }}=1\left(p \leq p_{c}\right)$ at time step $j$. Thus, the critical time scale for dissolution of the boundary was defined as $t_{c}$ $=j \tau_{\mathrm{r}}$ and $B=(1 / j)\left(D_{\mathrm{p}} / \tau_{\mathrm{r}}\right)^{1 / 2}$.

As $\beta$-gal release was highly affected by the presence of competitive cis-diols, we adapted our model to account for the effect of competitive displacement on $p$ and, thus, $P_{\text {sol }}$ at each time step. Here, we applied eq 3 to calculate $p$, accounting for $K_{\mathrm{eq}, \mathrm{D}}$ and [diol $]_{\mathrm{eff}}$, where [diol $]_{\text {eff }}$ is the effective concentration of the competitive cis-diol in the boundary layer. The true concentration of competitive diol in the boundary layer varies spatially and temporally based on diffusion into the gel, reversible binding with free and bound APBA moieties within the boundary layer, and the erosion of the boundary layer. A rigorous treatment of this problem was beyond the current work. Instead, we assumed that $[\mathrm{diol}]_{\mathrm{eff}}=[\mathrm{diol}]_{0}$, where $[\mathrm{diol}]_{0}$ is the concentration of competitive diol in the buffer.

In this manner, the model described the erosion rate with or without competitive displacement and returned a constant erosion rate, $B$. The erosion rate was combined with an expression for the mass loss of the gel based on the geometry of the gels that formed in the bottom of $2.0 \mathrm{~mL}$ reaction tubes as truncated cones:

$$
\frac{M(t)}{M_{0}}=1-\frac{\pi}{3 V_{0} \tan ^{2} \theta}\left[\left(h_{0}-B t\right)^{3}-h_{f}^{3}\right]
$$

where $h_{0}$ is the height of the full cone, $h_{\mathrm{f}}$ is the height of the truncated conical cap, $\theta$ is the angle of the cone, and $V_{0}$ is the volume of the gel. For $40 \mu \mathrm{L}$ gels formed at the bottom of the $2.0 \mathrm{~mL}$ reaction tubes, $h_{0}$ $=3.9 \mathrm{~mm}, h_{f}=1.22 \mathrm{~mm}$, and $\theta=51^{\circ}$. This resulted in a height, $h$, of the gel of $2.68 \mathrm{~mm}$. In all cases, we assumed a constant erosion rate and the mass loss ( $\beta$-gal release) for the gel samples was calculated using eq 5 and the calculated $B$.

Model Calculations. The model was written and executed in Python (version 3.7.6) using the NumPy (www.numpy.org) and SciPy (www.scipy.org) libraries. A constant erosion rate, B, was returned given the appropriate inputs for the specified system: $c_{\text {gel }}{ }^{0}=$ $[0.005,0.01,0.02 \mathrm{M}] ; f=[4,8] ; K_{\mathrm{eq}}=[195,240,370]$ for $T=37,25$, and $4{ }^{\circ} \mathrm{C}$, respectively; $\tau_{\mathrm{r}}=[1.2,3.3,20 \mathrm{~s}]$ for $T=37,25$, and $4{ }^{\circ} \mathrm{C}$, respectively; $[\text { diol }]_{0}=\left[0,1,10,50,100,170 \mathrm{mg} \mathrm{mL}^{-1}\right] ; K_{\mathrm{eq}, \mathrm{D}}=[40$, $20,3]$ for fructose, mannitol, and glucose, respectively.

\section{RESULTS AND DISCUSSION}

Fabrication of Ideal Dynamic Covalent Hydrogels through Boronic Ester Formation. Ideal dynamic covalent hydrogels were formed via boronic ester formation from 4-arm and 8-arm poly(ethylene glycol) (PEG) macromers $\left(M_{\mathrm{n}} \approx\right.$ $\left.10000 \mathrm{~g} \mathrm{~mol}^{-1}\right)$, end-functionalized with a phenylboronic acid derivative (APBA) or a cis-1,2-diol containing moiety (GL) (Figure 1a). Robust hydrogels formed quickly $(\approx 1-10 \mathrm{~s})$ after mixing equimolar amounts of PEG-APBA and PEG-GL. Rheometric analysis showed that the storage modulus, $G^{\prime}(\omega)$, and the loss modulus, $G^{\prime \prime}(\omega)$, of the gels scaled as $G^{\prime}(\omega) \propto \omega^{2}$ and $G^{\prime \prime}(\omega) \propto \omega^{1}$ at low $\omega$, following standard scaling for terminal relaxation in the Maxwell model of linear viscoelasticity. This confirmed that the boronic-ester-based hydrogels behaved as ideal reversible networks and could be modeled as a single Maxwell element with a spring and a dashpot in series (Figure 1b). 27,39 Indeed, the materials exhibited a well-defined plateau modulus, $G_{\mathrm{p}}$, and a single relaxation time, $\tau_{\mathrm{r}}$. Here, the shear plateau modulus, $G_{\mathrm{p}}$, describes the energy stored within the material upon small deformations and depends on the concentration of elastically active chains. The relaxation time, $\tau_{\mathrm{r}}$, depends on the dynamics of the reversible cross-links and represents the transition between elastic behavior, at high $\omega$, and viscous behavior, at lower $\omega .{ }^{25}$

In a dynamic covalent hydrogel, the network junctions are able to break and form reversibly. ${ }^{40}$ Therefore, the plateau modulus of the gels, $G_{\mathrm{p}}$, is related to the stability of the underlying boronic ester cross-links, as dictated by the equilibrium constant, $K_{\mathrm{eq}}{ }^{27}$ In addition, the dynamics of network strand rearrangement are characterized by $\tau_{\mathrm{r}}$, which is inversely related to the lifetime of the junction. ${ }^{41}$ To investigate the effects of the network dynamics, $\tau_{\mathrm{r}}$, and the binding equilibrium, $K_{\text {eq }}$ on release in dynamic covalent hydrogels, we calculated $\tau_{\mathrm{r}}$ and $K_{\mathrm{eq}}$ as a function of temperature using shear rheometry; $\tau_{\mathrm{r}}=[1.2,3.3,20 \mathrm{~s}]$ and $K_{\mathrm{eq}}=[195,240,370]$ for $T=37,25$, and $4{ }^{\circ} \mathrm{C}$, respectively (Figure $1 \mathrm{c}$ and $\mathrm{d}$ ).

Network Dynamics $\left(\tau_{\mathrm{r}}\right)$ and Binding Equilibrium $\left(K_{\mathrm{eq}}\right)$ Control Release in Dynamic Covalent Hydrogels. We prepared boronic-ester-based dynamic covalent hydrogels (4arm PEG-APBA/GL, $10 \mathrm{wt} / \mathrm{wt} \%$; $\mathrm{pH} 7.5$ ) with encapsulated $\beta$-galactosidase ( $\beta$-gal, a model bioactive enzyme; $10 \mathrm{mg}$ $\left.\mathrm{mL}^{-1}\right)$. The release rate for $\beta$-gal was comparable to the release rate for an IgG antibody (IgG-Atto 594) with and without a competitive diol, demonstrating that $\beta$-gal can be used as a model biologic (Figure S14; SI 5). To investigate how temperature influences the release of encapsulated biologics, we formed $\beta$-gal-loaded gels $(40 \mu \mathrm{L})$ at the bottom of $2.0 \mathrm{~mL}$ reaction tubes. The gels were immersed in phosphate buffer $(\mathrm{pH} 7.5 ; 2.0 \mathrm{~mL})$ at 4,25 , and $37^{\circ} \mathrm{C}$. At defined time points, the supernatant was assessed for $\beta$-gal activity by taking test samples $(50 \mu \mathrm{L})$. As encapsulated $\beta$-gal was released in its active form in all samples, $\beta$-gal activity, characterized via colorimetry, was used to quantify the fractional release of protein as a function of time, $\beta-\operatorname{gal}(t) / \beta-\operatorname{gal}_{0} . \beta-\operatorname{gal}(t)$ is the 
a) Enzyme release

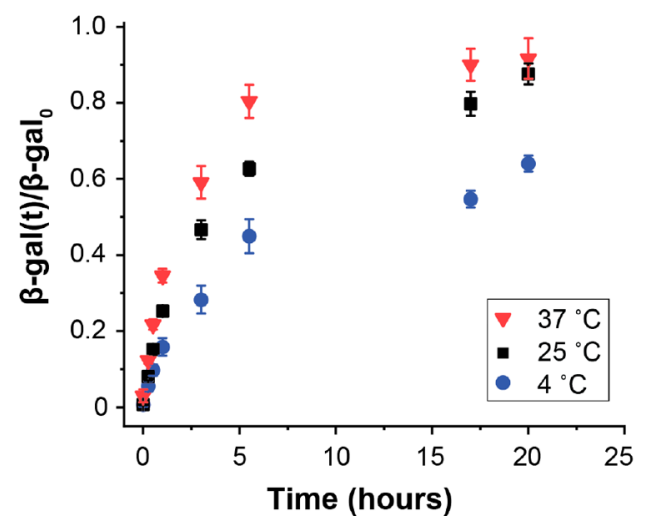

b) Mass loss

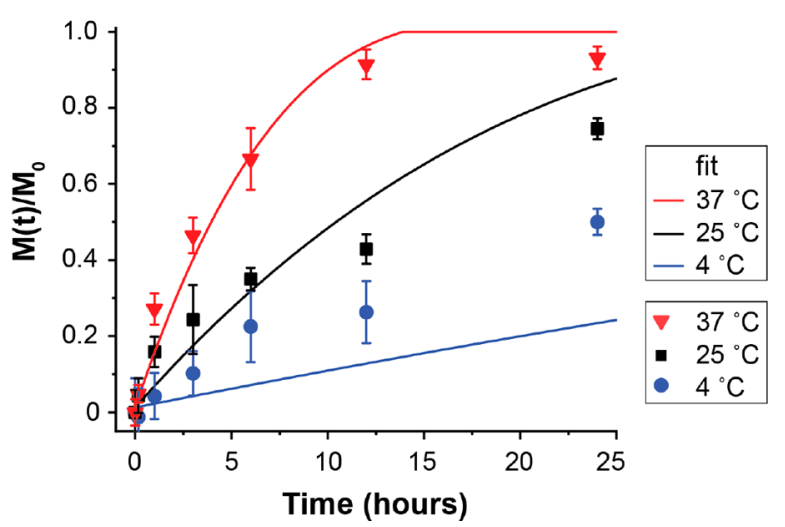

Figure 2. Release kinetics in boronic-ester-based hydrogels increased with temperature. (a) Fractional release of $\beta$-galactosidase over time, $\beta$ $\operatorname{gal}(t) / \beta$-gal ${ }_{0}$, and (b) fractional gel mass loss over time, $M(t) / M_{0}$, were determined at 4,25 , and $37{ }^{\circ} \mathrm{C}(4$-arm PEG-APBA/GL, $10 \mathrm{wt} / \mathrm{wt} \%$; $\mathrm{pH}$ $7.5 ; 2.0 \mathrm{~mL}$ ). In addition, $M(t) / M_{0}$ at 4,25 , and $37^{\circ} \mathrm{C}$ was fitted to our erosion-based release model (eq $\left.5 ; c_{\text {gel }}{ }^{0}=0.01 \mathrm{M}, f=4\right)$. All measurements are reported as triplicates with the mean \pm standard deviation.

cumulative amount of active $\beta$-gal released at time, $t$, and $\beta$-gal is the total amount of $\beta$-gal loaded into the gel initially.

The kinetics of release increased with $T$ (Figure 2a). As shown above, the dynamics, $\tau_{\mathrm{r}}$, and equilibrium constant, $K_{\text {eq }}$, in the boronic-ester-based gels vary with temperature; $\tau_{\mathrm{r}}$ and $K_{\text {eq }}$ both decrease with increasing $T$ (Figure 1b,c). This indicated that samples with faster dynamics (lower $\tau_{\mathrm{r}}$ ) and weaker binding (lower $K_{\text {eq }}$ ) between diol and boronic acid resulted in increased release kinetics. This is expected, as networks with faster dynamics rearrange more quickly and networks with weaker binding have a lower fraction of formed cross-links (boronic ester bonds). Both of these changes in the network properties could accelerate diffusion of $\beta$-gal through the gel (through decreased cross-link density and increased mesh size) and increase the rate of surface erosion of the gel (through decreased cross-link density, increased sol fraction, and increased free polymer chain mobility) (Figure 1d).

Erosion-Dominated Release of $\beta$-Gal Occurs at Elevated Temperatures. To investigate the relative extent of erosion-based release and diffusion-based release, we quantified the mass loss in non- $\beta$-gal-loaded gels with the same experimental conditions (Figure $2 \mathrm{~b}$ ). The mass loss data was plotted as $M(t) / M_{0}$, where $M(t)$ is the cumulative mass loss at time $t$ and $M_{0}$ is the total mass of the initial gel. If the process was dominated by erosion, we would expect the $\beta$-gal release and mass loss curves to superimpose. If the process was dominated by diffusion, we would expect cumulative $\beta$-gal release to outpace mass loss during the time course of the experiment. We observed an overlay of the $\beta$-gal release and mass loss curves at $37{ }^{\circ} \mathrm{C}$, whereas the enzyme release outpaced mass loss at 25 and $4{ }^{\circ} \mathrm{C}$ (Figure 2 and SI 6). This indicated that, at elevated $T$ (lower $\tau_{\mathrm{r}}$ and $\left.K_{\mathrm{eq}}\right), \beta$-gal release was erosion-dominated; at lower $T$, release occurred through a combination of $\beta$-gal diffusion and hydrogel erosion.

To compare the extent of erosion with the extent of diffusion, we considered their effective time scales in the system. We assumed a diffusion coefficient for $\beta$-gal, $D_{\beta \text { gal }}$, of $4.0 \mu \mathrm{m}^{2} \mathrm{~s}^{-1}$, based on similar diffusion coefficients for large biomolecules in $10 \mathrm{wt} / \mathrm{wt} \%$ PEG-based hydrogels. ${ }^{30}$ The gels were formed in the bottom of $2.0 \mathrm{~mL}$ reaction tubes as truncated cones with a height, $h$, of $2.68 \mathrm{~mm}$ for $40 \mu \mathrm{L}$ gels. A characteristic time scale for pure diffusion was defined as $\tau_{\mathrm{D}}=$ $h^{2} / 4 D_{\beta \text { gal }} \approx 125 \mathrm{~h}$, and a characteristic time scale for erosion was defined as $\tau_{\mathrm{E}}=h / 2 B$, where $B$ is the erosion rate $(\mathrm{mm}$ $\mathrm{h}^{-1}$ ). We defined a dimensionless parameter to characterize the ratio of the kinetics of erosion to diffusion in the system as $\alpha=$ $B h / 2 D_{\beta \text { gal }}$ following the analysis of Lee. ${ }^{31}$ In this approach, diffusion can be ignored when $\alpha \geq 10$, which corresponded to a critical erosion rate of $0.11 \mathrm{~mm} \mathrm{~h}^{-1}$ for our system. This implied an approximate erosion time of $12 \mathrm{~h}$, and therefore, we assumed that any release that occurred in $12 \mathrm{~h}$ or less $(B \geq$ $0.11 \mathrm{~mm} \mathrm{~h}^{-1}$ ) to be erosion-dominated.

To estimate the erosion rates from mass loss data, we fit an expression for the expected mass loss profile in the truncated conical gels given a constant erosion rate, $B$. Fitting eq 5 to the first $6 \mathrm{~h}$ of the mass loss data resulted in estimated erosion rates of $0.048,0.088$, and $0.24 \mathrm{~mm} \mathrm{~h}^{-1}$ for 4,25 , and $37{ }^{\circ} \mathrm{C}$, respectively, corresponding to $\alpha=4.5,8.2$, and 22.3. This analysis indicated that $\beta$-gal release was erosion-dominated at $37^{\circ} \mathrm{C}(\alpha>10$; total time of release $\approx 12 \mathrm{~h})$, mostly erosion at $25{ }^{\circ} \mathrm{C}(\alpha \approx 10$; total time of release $<24 \mathrm{~h})$, and a mixture of erosion and diffusion at $4{ }^{\circ} \mathrm{C}(\alpha<10$; total time of release $>24$ $\mathrm{h})$. This was supported by the overlay of the mass loss and release data at $37^{\circ} \mathrm{C}$ (SI 6). In addition, we observed swelling of the hydrogel samples at 25 and, especially, at $4{ }^{\circ} \mathrm{C}$, which further complicated release in nonerosion-dominated samples (SI 7).

Competitive Displacement Accelerates Erosion in Dynamic Covalent Hydrogels. Competitive displacement of boronic ester cross-links via the addition of cis-diol containing moieties modulates the cross-linking density and/ or dissolves boronic-ester-based dynamic covalent hydrogels (SI 8). ${ }^{19}$ As such, these gels have been used as glucoseresponsive drug delivery systems, where release is controlled by the local glucose concentration through network changes upon glucose binding. ${ }^{19,21,42}$ However, there is limited data on the relative effect of different cis-diol containing moieties, including non-glucose sugars, on release in boronic-ester-based hydrogels. To investigate systematically the influence of cis-diol containing sugars on release, we prepared $\beta$-gal-loaded gels for release into phosphate buffer $\left(\mathrm{pH} 7.5,25{ }^{\circ} \mathrm{C} ; 2.0 \mathrm{~mL}\right)$ containing fructose, mannitol, or glucose $\left(100 \mathrm{mg} \mathrm{mL}^{-1} ; 0.55\right.$ $\mathrm{M})$. In each case, the addition of sugar accelerated release relative to a control without competitive displacement and the 
a) Sugar type

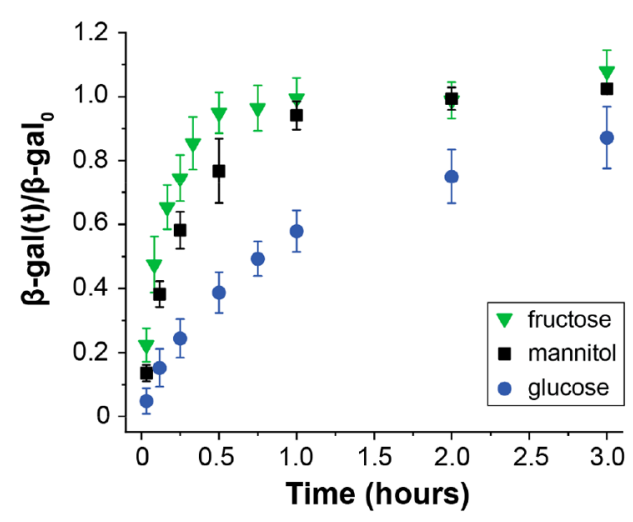

c) Polymer content

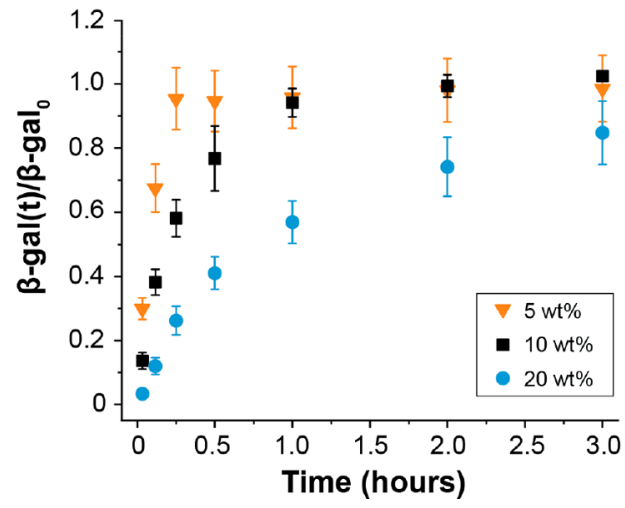

b) Sugar concentration (mannitol)

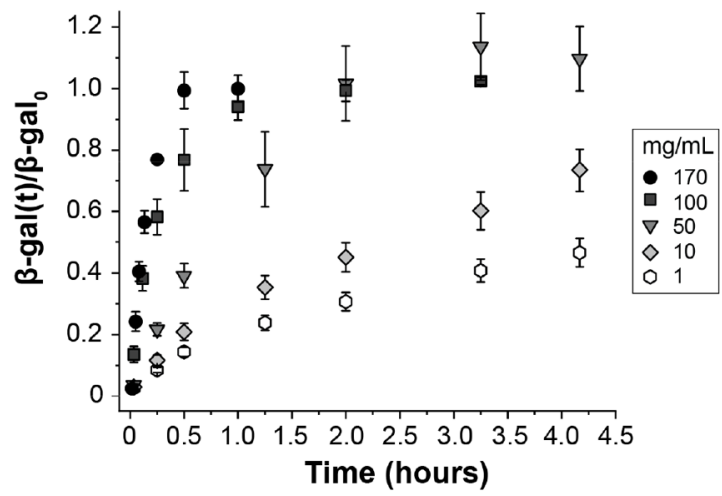

d) Network architecture

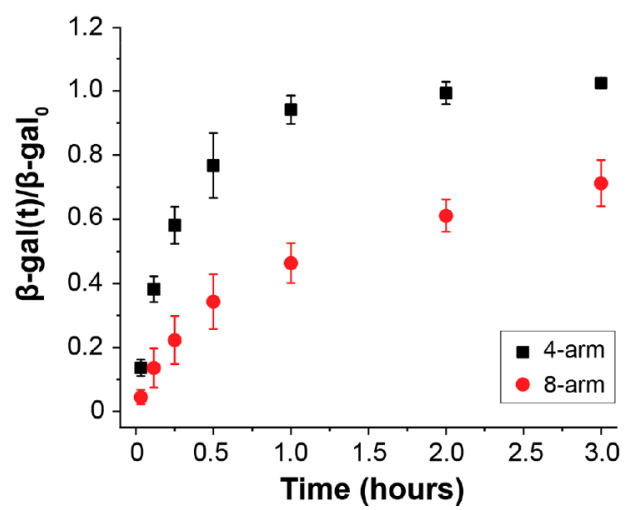

Figure 3. Environmental conditions and network architecture dictate the release kinetics in boronic-ester-based hydrogels. Different release buffers were formulated to study (a) the influence of disparate cis-diol containing sugars (fructose, mannitol, or glucose; $100 \mathrm{mg} \mathrm{mL} \mathrm{m}^{-1} ; 0.55 \mathrm{M}$ ) and (b) the effect of varying the sugar concentration (mannitol; $1-170 \mathrm{mg} \mathrm{mL}^{-1} ; 0.0055-1.1 \mathrm{M}$ ) on the fractional release of $\beta$-galactosidase over time, $\beta$ -

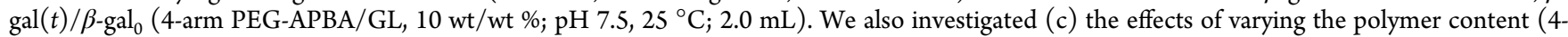
arm PEG-APBA/GL; 5, 10, or $20 \mathrm{wt} / \mathrm{wt} \%$ ) and (d) the functionality of the networks (4-arm or 8-arm PEG-APBA/GL; $10 \mathrm{wt} / \mathrm{wt} \%)$, by fixing the content of the release buffer $\left(100 \mathrm{mg} \mathrm{mL}^{-1}\right.$ mannitol; $\left.\mathrm{pH} 7.5,25{ }^{\circ} \mathrm{C} ; 2.0 \mathrm{~mL}\right)$. All measurements are reported as triplicates with the mean \pm standard deviation.

release was erosion-dominated (time of release $<12 \mathrm{~h}$; Figure $3 a)$. The addition of fructose led to the fastest release/erosion, followed by mannitol, and then glucose. Supporting Information Movie 1 shows a 5 min time-lapse of a bolus gel that was released in $100 \mathrm{mg} \mathrm{mL}^{-1}$ fructose (4-arm PEG APBA/GL, $10 \mathrm{wt} / \mathrm{wt} \%$; $\left.\mathrm{pH} 7.5,25{ }^{\circ} \mathrm{C}\right)$, demonstrating erosion-dominated release. The sample was loaded with a small molecule dye (rhodamine B; $0.5 \mathrm{mg} \mathrm{mL}^{-1}$ ) for visualization.

To understand $\beta$-gal release and gel erosion in the presence of a competitive cis-diol, we measured the equilibrium binding constant, $K_{\text {eq,D, }}$ between different boronic acids (2-FPBA, DAPBA, or PEG-APBA) and each of the sugars using a fluorescence-based assay. For PEG-APBA, $K_{\text {eq, }}$ was calculated as 40, 20, and 3 for fructose, mannitol, and glucose, respectively. Thus, the rate of release/erosion scaled with $K_{\mathrm{eq}, \mathrm{D}}$. Further, this demonstrates that boronic-ester-based materials are more sensitive to other cis-diols than glucose, which should be considered when designing responsive drug delivery systems for in vivo application. In fact, studies have shown that the most stable boronic-acid-diol complexes are formed with diols on furanose rings. This explains how $K_{\mathrm{eq}, \mathrm{D}}{ }^{\text {fructose }} \gg K_{\mathrm{eq}, \mathrm{D}}{ }^{\text {glucose }}$, despite their structural similarities, as the natural composition of glucose is $0.14 \%$ furanose, while fructose is composed of $25 \%$ furanose. . $^{20,43}$

While temperature modulated $K_{\mathrm{eq}}$ and $\tau_{\mathrm{r}}$ in the gel, competitive displacement affected network behavior by shifting the equilibrium binding of APBA and GL, leading to a decrease in the local cross-link density in the gel. The fraction of bound boronic esters, $p$, was calculated by treating the addition of a second cis-diol as a competitive inhibition (eq 3). ${ }^{35}$ Equation 3 was solved for $p$ in each case and described how increasing $K_{\text {eq,D }}$ decreased the local fraction of bound boronic esters or cross-link density. When $p$ dropped below $p_{\mathcal{c}}$ the critical percolation threshold, the network passed through a reverse gel point and dissolved. ${ }^{28}$

Erosion Rate Depends on the Concentration of the Competitive Diol. As the fraction of bound boronic esters depends on $K_{\mathrm{eq}, \mathrm{D}}$ and [diol], we investigated the release behavior in buffers with a range of mannitol concentration (1$\left.170 \mathrm{mg} \mathrm{mL}{ }^{-1} ; 0.0055-1.1 \mathrm{M}\right)$. As expected, the release rate increased with increasing [diol] and the release was dominated by erosion in all cases (Figure $3 \mathrm{~b}$; time of release $\leq 12 \mathrm{~h}$ ). While the addition of a competitive diol alters $p$, which can influence both the rate of erosion and the rate of diffusion of the biologic within the gel, the effect on $\beta$-gal diffusion was not 
a) Erosion-based release model

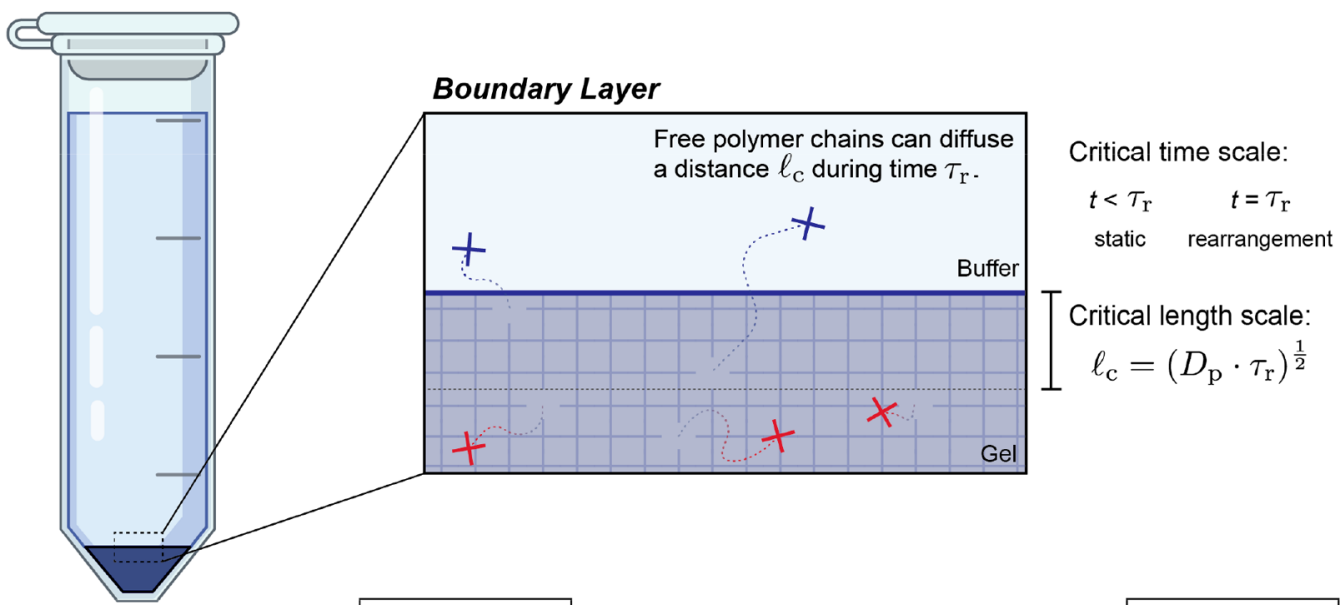

\section{b) Enzyme release predictions}

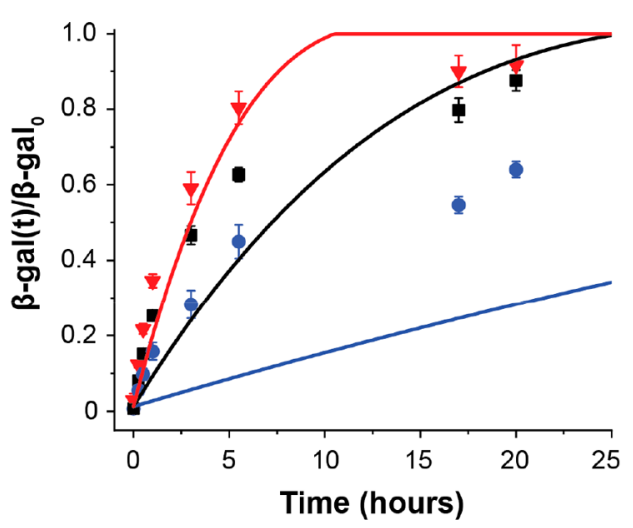

c) Mass loss predictions
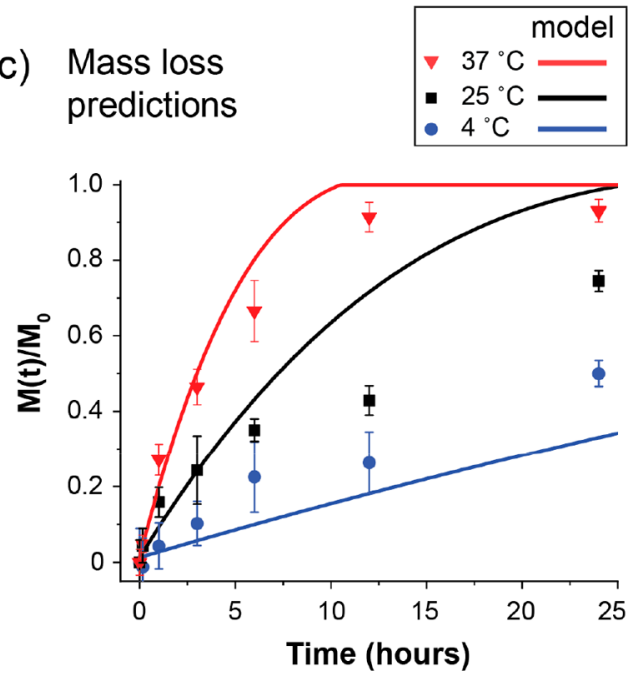

Figure 4. Erosion at the surface of dynamic covalent hydrogels predicts biomolecule release. (a) A statistical model was developed to describe the observed release based on the binding equilibria in a boundary layer at the interface between the gels and the buffer. The erosion rate, $B$, was determined from the characteristic length scale of the boundary layer, $l_{c}$ (set by the diffusion of free polymer), and the characteristic time scale of the system, $\tau_{\mathrm{r}}$ (the relaxation time of the network). After $B$ was calculated, eq 5 was used to model the release at 4,25 , and $37^{\circ} \mathrm{C}(\mathrm{PEG}-\mathrm{APBA} / \mathrm{GL}$; $\left.c_{\text {gel }}{ }^{0}=0.01 \mathrm{M}, f=4\right)$. Model predictions were compared with $(\mathrm{b})$ the fractional release of $\beta$-galactosidase over time, $\beta$-gal $(t) / \beta$-gal ${ }_{0}$, and $(\mathrm{c})$ the fractional gel mass loss over time, $M(t) / M_{0}$ (4-arm PEG-APBA/GL, $10 \mathrm{wt} / \mathrm{wt} \%$; $\mathrm{pH} 7.5 ; 2.0 \mathrm{~mL}$ ). All measurements are reported as triplicates with the mean \pm standard deviation.

considered as we observed erosion-dominated release in all samples.

These data demonstrated how the concentration of an exogenous diol can be used to tailor release from boronicester-based dynamic covalent hydrogels. While diol-responsive behavior is useful and has been applied to design glucosetriggered drug delivery systems, both the equilibrium binding constant, $K_{\mathrm{eq}, \mathrm{D}}$, and the concentrations of all potential cis-diols should be considered when designing such systems, as the addition of small amounts of mannitol $\left(K_{\mathrm{eq}, \mathrm{D}}\right.$ mannitol $\gg$ $K_{\text {eq,D }}$ glucose $)$ significantly accelerated erosion in these gels.

Increased Network Density Slows Erosion-Based Release. In addition to the concentration of the competitive diol, we investigated how the network density (wt/wt \%) and functionality, $f$, influenced erosion-based release. Here, we fixed the content of the phosphate release buffer $(100 \mathrm{mg}$ $\mathrm{mL}^{-1}$ mannitol; $\mathrm{pH} 7.5 ; 2.0 \mathrm{~mL} ; 25{ }^{\circ} \mathrm{C}$ ) and varied the polymer content $(5,10$, and $20 \mathrm{wt} / \mathrm{wt} \% ; f=4)$ or the functionality $(f=4$ or $8 ; 10 \mathrm{wt} / \mathrm{wt} \%)$. As expected, decreasing the polymer content accelerated erosion in the dynamic covalent hydrogels, whereas increasing the polymer content or the functionality slowed erosion (Figure $3 c, d$ ). This can be understood by considering the role of $p_{c}, p$, and $P_{\text {sol }}$ on erosion in these networks. The critical extent of reaction to ensure gelation, $p_{\mathrm{c}}$, depends on $f: p_{\mathrm{c}}=0.33$ for $f=4$ and $p_{\mathrm{c}}=0.14$ for $f$ $=8$. Thus, increasing the connectivity of the network, $f$, requires a lower fraction of bound esters before the network dissolves, slowing the rate of erosion. Further, $p$ and $P_{\text {sol }}$ both depend on wt/wt $\%$ and $f$, such that increasing wt/wt $\%$ or $f$ leads to a corresponding increase in $p$ and decrease in $P_{\text {sol }}$. As observed, both effects slow erosion in dynamic covalent hydrogels.

A Statistical Model Describes Erosion-Based Release in Dynamic Covalent Hydrogels. To describe erosionbased release in dynamic covalent hydrogels, we developed a statistical model of biomolecule release from the boronic-esterbased hydrogels. As the rate of $\beta$-gal diffusion was slow compared to the observed erosion rates $\left(\alpha=B h / 2 D_{\beta \text { gal }}>10\right)$, we constrained the model to surface erosion of the gels. Therefore, we focused our analysis on the behavior of a 
a) Sugar type

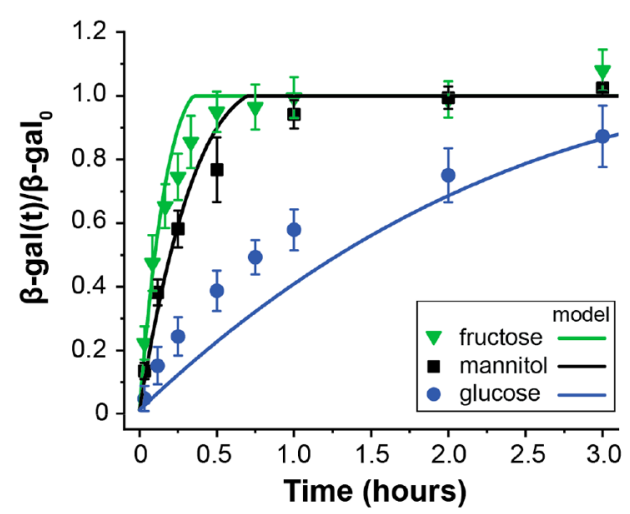

c) Polymer content

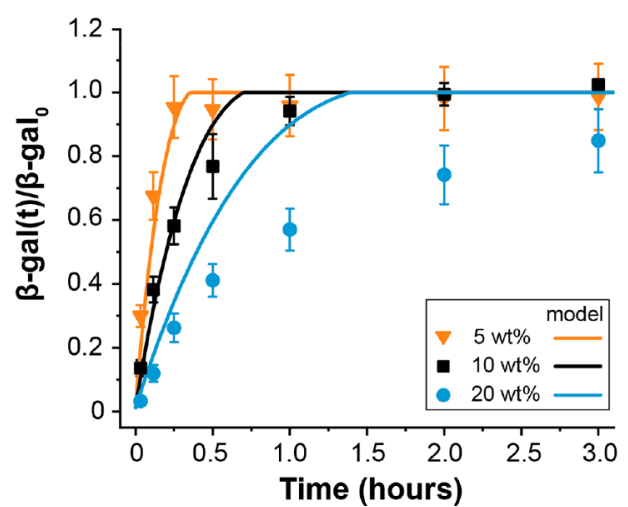

b) Sugar concentration (mannitol)

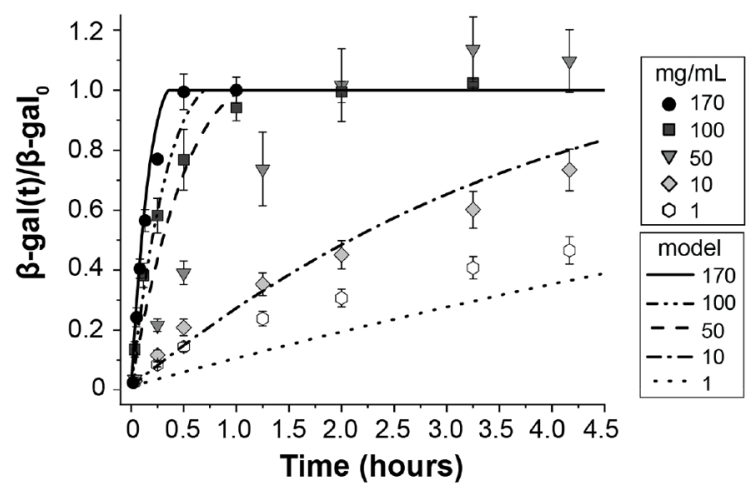

d) Network architecture

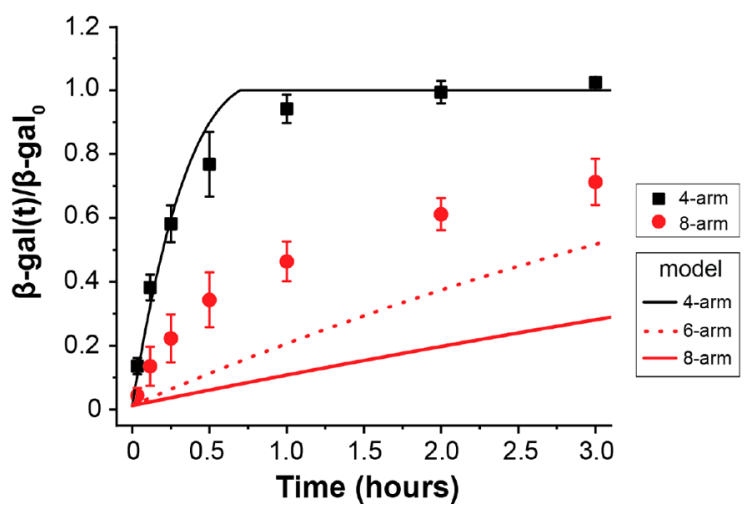

Figure 5. Statistical model describing the influence of environment and network architecture on release in boronic-ester-based hydrogels. (a) Effects of sugar type (fructose, mannitol, or glucose, $\left.100 \mathrm{mg} \mathrm{mL}^{-1} ; c_{\text {gel }}^{0}=0.01 \mathrm{M}, f=4\right)$ ), (b) sugar concentration $\left(\mathrm{mannitol}^{0}, 1-170 \mathrm{mg} \mathrm{mL}^{-1}\right.$; $c_{\text {gel }}{ }^{0}$ $=0.01 \mathrm{M}, f=4)$, (c) polymer content $\left(c_{\text {gel }}{ }^{0}=0.005,0.01\right.$, or $\left.0.02 \mathrm{M} ; f=4\right)$, and (d) network architecture $\left(c_{\text {gel }}{ }^{0}=0.01 ; f=4,6\right.$ or 8$)$ on the fractional release of $\beta$-galactosidase over time, $\beta$-gal $(t) / \beta$-gal ${ }_{0}$ (PEG-APBA/GL; $\mathrm{pH} 7.5,25^{\circ} \mathrm{C} ; 2.0 \mathrm{~mL}$ ), were described by the erosion-based model (eq 5). All measurements are reported as triplicates with the mean \pm standard deviation.

boundary layer at the interface between the hydrogel and the release buffer (Figure 4a). ${ }^{29,32}$ We set a characteristic time scale for the system as the relaxation time, $\tau_{\mathrm{r}}$, of the hydrogel. The network structure of the gel was treated as static for $t<\tau_{\mathrm{r}}$, and the network was allowed to rearrange at $t=\tau_{\mathrm{r}}$. To define a length scale of the boundary layer, we considered the distance that a free (nonassociated) polymer chain can diffuse during the relaxation time, $l_{\mathrm{c}}=\left(D_{\mathrm{p}} \tau_{\mathrm{r}}\right)^{1 / 2}$, where $D_{\mathrm{p}}$ is the diffusion coefficient of a nonassociated polymer chain. We assumed that $D_{\mathrm{p}}=15 \mu \mathrm{m}^{2} \mathrm{~s}^{-1}$ in the boundary layer during the relaxation time, as we treated free polymer chains as nonassociating polymers in this regime. ${ }^{34}$ As the diffusion coefficient for associating polymers in associating polymer networks is orders of magnitude smaller than that of nonassociating polymers, we treated the boundary layer as an isolated system that did not exchange mass with other layers of the gel. ${ }^{33}$

We then defined an erosion rate $B=l_{c} / t_{c}$, where $t_{c}$ is the critical time required to dissolve this boundary layer. In the case where the boundary layer dissolves within $\tau_{\mathrm{r}}, t_{\mathrm{c}}$ was equated with $\tau_{\mathrm{r}}$ and $B=\left(D_{\mathrm{p}} / \tau_{\mathrm{r}}\right)^{1 / 2}$. When the boundary layer did not dissolve within $\tau_{\mathrm{r}}$, we estimated the critical time for the boundary layer to dissolve, $t_{\mathcal{c}}$, using the statistical model based on the binding equilibrium between network forming species, a mean-field description of network connectivity, and free polymer chain diffusion. ${ }^{28,29}$ Here, the critical time scale for dissolution of the boundary was defined as $t_{\mathrm{c}}=j \tau_{\mathrm{r}}$ and $B=(1 /$
$j)\left(D_{\mathrm{p}} / \tau_{\mathrm{r}}\right)^{1 / 2}$, where $j$ is the number of time steps of $\tau_{\mathrm{r}}$ required to dissolve the boundary layer. In all cases, we assumed a constant erosion rate and the mass loss ( $\beta$-gal release) for the gel samples was predicted using eq 5 and the calculated $B$. Based on this model, we can see that the rate of erosion scales with $\tau_{\mathrm{r}}^{-1 / 2}$. This was consistent with our data that the erosion rate decreased with $T$ (Figure $2 \mathrm{~b}$ ), as the rheometric analysis showed that gels at lower $T$ had longer $\tau_{\mathrm{r}}$ (Figure $1 \mathrm{~b}$ ).

We compared our model of erosion in dynamic covalent hydrogels with the observed enzyme release and the mass loss data of PEG-APBA/GL gels (10 wt/wt \%) immersed in phosphate buffer $(\mathrm{pH} 7.5 ; 2.0 \mathrm{~mL})$ at 4,25 , and $37{ }^{\circ} \mathrm{C}$ (Figure 4). We used $K_{\mathrm{eq}}$ and $\tau_{\mathrm{r}}$ values measured from the shear rheometry ( 365 and $20 \mathrm{~s}$ at $4{ }^{\circ} \mathrm{C} ; 240$ and $3.3 \mathrm{~s}$ at $25^{\circ} \mathrm{C}$; 195 and $1.2 \mathrm{~s}$ at $37^{\circ} \mathrm{C}$ ) and known physical parameters for the gel $\left(c_{\text {gel }}{ }^{0}=0.01 \mathrm{M}, f=4\right)$. The model fit both the enzyme release and the mass loss data well at $37^{\circ} \mathrm{C}$, where $\alpha>10$ and erosion dominated (Figure 4b,c). The model also described mass loss at 4 and $25{ }^{\circ} \mathrm{C}$ reasonably well (Figure $4 \mathrm{c}$ ), but the predictions diverged from the observed enzyme release at 4 and $25{ }^{\circ} \mathrm{C}$ (Figure 4b). In particular, at $4{ }^{\circ} \mathrm{C}$, where $\alpha<10$, we hypothesized that increased diffusion of $\beta$-gal due to swelling could account for the differences. Thus, our model described erosion-dominated mass loss without any fitting parameter.

As $\beta$-gal release in the presence of competitive cis-diols occurred in the erosion-dominated regime $(\alpha>10)$, we 
adapted our model to account for the effect of competitive displacement on $p$ and, thus, $P_{\text {sol }}$. We then applied our model to describe the release of $\beta$-gal from the gels with disparate competitive diols: fructose, mannitol, and glucose (Figure 5a); different concentrations of mannitol (Figure 5b); and different network architectures (Figure 5c,d). In general, our model agreed with the observed release in the presence of a competitive diol. One exception was for the samples composed of 8 -arm PEG-APBA/GL at $10 \mathrm{wt} / \mathrm{wt} \%$ in $100 \mathrm{mg} \mathrm{mL}^{-1}$ mannitol. This deviation is likely caused by differences between the real reverse gel point and the predicted reverse gel point based on incomplete functionalization or the formation of loop defects. Model predictions for networks composed of 6-arm PEG-APBA/GL led to a closer agreement with the observation (Figure $5 \mathrm{~d}$ ). In total, for $T=25^{\circ} \mathrm{C}$, the model predicted erosion rates with competitive displacement from $0.19 \mathrm{~mm} \mathrm{~h}^{-1}$ (10 wt/wt \% in $1 \mathrm{mg} \mathrm{mL}^{-1}$ mannitol) to the maximum erosion rate under the model for these conditions $B_{\max }=7.7 \mathrm{~mm} \mathrm{~h}^{-1}\left(5 \mathrm{wt} / \mathrm{wt} \%\right.$ in $100 \mathrm{mg} \mathrm{mL}^{-1}$ mannitol and $10 \mathrm{wt} \%$ in $100 \mathrm{mg} \mathrm{mL}^{-1}$ fructose or $170 \mathrm{mg} \mathrm{mL}^{-1}$ mannitol; $f$ $=4)$.

The agreement between the statistical model and the observed release data highlighted the importance of surface erosion in biomolecule release from dynamic covalent hydrogels. The model evaluated surface erosion in a boundary layer that was defined by a characteristic time scale of the system, $\tau_{\mathrm{r}}$, and a length scale set by the diffusion of free polymer chains and was sufficient to describe release across a broad range of experimental conditions. Importantly, the model captured the influence of network properties and of the environmental conditions (temperature and concentration of competitive binders) on release in boronic-ester-based hydrogels.

In total, the release data and model together provide a framework for the design of dynamic covalent hydrogels for controlled release. Our analysis emphasized the importance of the binding equilibria in the gel, relaxation time of the gel, and free polymer diffusion within the gel on surface erosion and associated release. Thus, we need to tailor the network design and the selected dynamic chemistry based on the desired release profile and application environment when engineering dynamic covalent hydrogels for drug delivery. Further, it is necessary to consider the presence of any potential competitive binders in the local environment, which can affect the binding equilibrium of the gel-forming cross-links (and thus release) even at low concentrations.

\section{CONCLUSION}

In this work, we characterized biomolecule release from boronic-ester-based dynamic covalent hydrogels using a model biologic ( $\beta$-galactosidase). We systematically investigated the role of network properties and of the external environment (temperature and concentration of competitive binders) on $\beta$ gal release. We observed that the rate of release increased with increased temperature (lower $\tau_{\mathrm{r}}$ and $K_{\text {eq }}$ ) or concentration of competitive diol and decreased with increased network density. Overall, we found that surface erosion (and associated mass loss) governed $\beta$-gal release. To describe the observed release rates, we developed a statistical model of surface erosion based on the binding equilibria in a boundary layer at the surface of the gel. The model demonstrated how the binding equilibria in the gel, relaxation time of the gel, and free polymer diffusion within the gel together controlled surface erosion (and thus release) in boronic-ester-based gels. In total, our results will guide the design of dynamic covalent hydrogels as biomaterials for drug delivery applications. One potential limitation to translation of boronic ester-based materials is that certain boronic acids and their derivatives have been shown to act as chemical mutagens. ${ }^{44}$ While polymeric forms of the boronic acids have been shown to be safe for cell culture, ${ }^{19,23}$ more work needs to be done to determine whether specific boronic acid based materials are suitable for clinical application.

\section{ASSOCIATED CONTENT}

\section{SI Supporting Information}

The Supporting Information is available free of charge at https://pubs.acs.org/doi/10.1021/acs.biomac.0c00895.

${ }^{1} \mathrm{H}$ NMR spectra; fractional release of $\beta$-galactosidase at different loadings from the gels; titration curves used to determination $K_{\mathrm{eq}, \mathrm{D}}$; plateau modulus of gels at different polymer concentrations used to determine $K_{\text {eq }}$ IgG-Atto 594 release; swelling of gels during mass loss experiments (PDF)

Time lapse $(5 \mathrm{~min})$ of bolus gel released in $100 \mathrm{mg}$ $\mathrm{mL}^{-1}$ fructose, demonstrating erosion-dominated release MOV)

\section{AUTHOR INFORMATION}

\section{Corresponding Author}

Mark W. Tibbitt - Macromolecular Engineering Laboratory, Department of Mechanical and Process Engineering, ETH Zurich, 8092 Zurich, Switzerland; 이이이.org/0000-00024917-7187; Phone: +41 4463225 16; Email: mtibbitt@ ethz.ch

\section{Authors}

Bruno Marco-Dufort - Macromolecular Engineering Laboratory, Department of Mechanical and Process Engineering, ETH Zurich, 8092 Zurich, Switzerland; (1) orcid.org/0000-0001-9098-9964

Jack Willi - Macromolecular Engineering Laboratory, Department of Mechanical and Process Engineering, ETH Zurich, 8092 Zurich, Switzerland

Felipe Vielba-Gomez - Macromolecular Engineering Laboratory, Department of Mechanical and Process Engineering, ETH Zurich, 8092 Zurich, Switzerland

Francesco Gatti - Macromolecular Engineering Laboratory, Department of Mechanical and Process Engineering, ETH Zurich, 8092 Zurich, Switzerland

Complete contact information is available at:

https://pubs.acs.org/10.1021/acs.biomac.0c00895

\section{Author Contributions}

B.M.D. and M.W.T. conceived the ideas and designed the experiments. B.M.D., J.W., F.V.G., and F.G. executed the experiments and analyzed the data. B.M.D. and M.W.T. developed the model and interpreted the data. B.M.D. and M.W.T. wrote the manuscript with assistance from all authors. All authors have approved the final version of the manuscript.

\section{Notes}

The authors declare the following competing financial interest(s): This work was supported, in part, by Nanoly Bioscience, Inc., a startup that seeks to apply dynamic covalent hydrogels for the thermal stabilization and release of biologics. M.W.T. has a financial interest in Nanoly Bioscience, Inc. 
B.M.D. and M.W.T. are inventors on a patent related to the use of dynamic covalent hydrogels for the encapsulation, stabilization, and release of biomacromolecules.

\section{ACKNOWLEDGMENTS}

This work was funded by ETH Zürich, the Claude \& Giuliana Foundation, and Nanoly Bioscience, Inc.

\section{ABBREVIATIONS}

APIs, active pharmaceutical ingredients; DDS, drug delivery systems; PEG, poly(ethylene glycol); PBA, phenylboronic acid derivative; 2-FPBA, 2-formylphenylboronic acid; DAPBA, 2((dimethylamino)methyl)phenylboronic acid; $\beta$-gal, $\beta$-galactosidase; IgG, IgG-Atto 594; GL, gluconolactone; APBA, orthoaminomethylphenylboronic acid; ONPG, ortho-nitrophenyl $\beta$ D-galactopyranoside; ARS, Alizarin Red S; FS, frequency sweep; $T$, temperature; $M_{n}$, number-average molecular weight; $\gamma$, strain; $\omega$, angular frequency; $M(t)$, cumulative mass lost at time $t ; M_{0}$, total mass of initial gel; $\beta$-gal $(t)$, cumulative amount of active $\beta$-gal released at time $t ; \beta$-gal , total amount of $\beta$-gal loaded in gel initially; $K_{\text {eq }}$, equilibrium constant (between the boronic acid and the diol that comprise the network); $K_{\text {eqD }}$, equilibrium binding constant (between the boronic acid and the competitive diol); $G_{\mathrm{p}}$, plateau modulus; $\tau_{\mathrm{r}}$, relaxation time; $\Delta G_{\mathrm{r}}^{0}$, reaction Gibbs free energy; $R$, gas constant; $D_{\beta \text {-gal }}$ diffusion coefficient for $\beta$-gal; $h$, height of the gel; $\tau_{\mathrm{D}}$, characteristic time scale for pure diffusion; $\tau_{\mathrm{E}}$, characteristic time scale for erosion; $B$, erosion rate; $\alpha$, dimensionless parameter to characterize the ratio of erosion/diffusion kinetics; $l_{c}$ critical length scale of the boundary layer; $D_{p}$, diffusion coefficient for nonassociating polymer chain; $p$, fraction of bound esters; $c_{\text {gel }}$, concentration of the network in the boundary layer; $c_{\text {gel }}^{0}$, initial concentration of the network; $f$, functionality of the network forming polymers; $P_{\text {sol }}$, sol fraction at the boundary layer; $p_{\mathcal{c}}$ critical percolation threshold; $t_{\mathcal{C}}$ critical time required to dissolve the boundary layer; $[\text { diol }]_{\text {eff }}$ effective concentration of diol at the boundary layer; $[\mathrm{diol}]_{0}$, concentration of diol in the buffer; $\kappa$, modified Hill parameter; $h_{0}$, height of the full cone; $h_{\mathrm{f}}$, height of the truncated conical cap; $\theta$, angle of the cone; $V_{0}$, total volume of the gel; $B_{\max }$ maximum erosion rate

\section{REFERENCES}

(1) Leader, B.; Baca, Q. J.; Golan, D. E. Protein Therapeutics: A Summary and Pharmacological Classification. Nat. Rev. Drug Discovery 2008, 7, 21-39.

(2) Anselmo, A. C.; Gokarn, Y.; Mitragotri, S. Non-Invasive Delivery Strategies for Biologics. Nat. Rev. Drug Discovery 2019, 18, 19-40.

(3) Tibbitt, M. W.; Dahlman, J. E.; Langer, R. Emerging Frontiers in Drug Delivery. J. Am. Chem. Soc. 2016, 138, 704-717.

(4) Li, J.; Mooney, D. J. Designing Hydrogels for Controlled Drug Delivery. Nat. Rev. Mater. 2016, 1, 16071.

(5) Peppas, N. A.; Hilt, J. Z.; Khademhosseini, A.; Langer, R. Hydrogels in Biology and Medicine: From Molecular Principles to Bionanotechnology. Adv. Mater. 2006, 18, 1345-1360.

(6) Peppas, N. A.; Bures, P.; Leobandung, W.; Ichikawa, H. Hydrogels in Pharmaceutical Formulations. Eur. J. Pharm. Biopharm. 2000, 50, 27-46.

(7) Lin, C. C.; Metters, A. T. Hydrogels in Controlled Release Formulations: Network Design and Mathematical Modeling. Adv. Drug Delivery Rev. 2006, 58, 1379-1408.

(8) Lutolf, M. P.; Lauer-Fields, J. L.; Schmoekel, H. G.; Metters, A. T.; Weber, F. E.; Fields, G. B.; Hubbell, J. A. Synthetic Matrix Metalloproteinase-Sensitive Hydrogels for the Conduction of Tissue
Regeneration: Engineering Cell-Invasion Characteristics. Proc. Natl. Acad. Sci. U. S. A. 2003, 100, 5413-5418.

(9) Boontheekul, T.; Kong, H. J.; Mooney, D. J. Controlling Alginate Gel Degradation Utilizing Partial Oxidation and Bimodal Molecular Weight Distribution. Biomaterials 2005, 26, 2455-2465.

(10) Tibbitt, M. W.; Han, B. W.; Kloxin, A. M.; Anseth, K. S. Synthesis and Application of Photodegradable Microspheres for Spatiotemporal Control of Protein Delivery. J. Biomed. Mater. Res., Part A 2012, 100, 1647-1654.

(11) Macarthur, J. W.; Purcell, B. P.; Shudo, Y.; Cohen, J. E.; Fairman, A.; Trubelja, A.; Patel, J.; Hsiao, P.; Yang, E.; Lloyd, K.; Hiesinger, W.; Atluri, P.; Burdick, J. A.; Woo, Y. J. Sustained Release of Engineered Stromal Cell-Derived Factor 1- $\alpha$ from Injectable Hydrogels Effectively Recruits Endothelial Progenitor Cells and Preserves Ventricular Function after Myocardial Infarction. Circulation 2013, 128, S79-86.

(12) O’Shea, T. M.; Aimetti, A. A.; Kim, E.; Yesilyurt, V.; Langer, R. Synthesis and Characterization of a Library of In-Situ Curing, Nonswelling Ethoxylated Polyol Thiol-Ene Hydrogels for Tailorable Macromolecule Delivery. Adv. Mater. 2015, 27, 65-72.

(13) Webber, M. J.; Appel, E. A.; Meijer, E. W.; Langer, R. Supramolecular Biomaterials. Nat. Mater. 2016, 15, 13-26.

(14) Guvendiren, M.; Lu, H. D.; Burdick, J. A. Shear-Thinning Hydrogels for Biomedical Applications. Soft Matter 2012, 8, 260-272.

(15) Appel, E. A.; del Barrio, J.; Loh, X. J.; Scherman, O. A. Supramolecular Polymeric Hydrogels. Chem. Soc. Rev. 2012, 41, 6195-6214.

(16) Appel, E. A.; Tibbitt, M. W.; Webber, M. J.; Mattix, B. A.; Veiseh, O.; Langer, R. Self-Assembled Hydrogels Utilizing PolymerNanoparticle Interactions. Nat. Commun. 2015, 6, 6295.

(17) Steele, A. N.; Stapleton, L. M.; Farry, J. M.; Lucian, H. J.; Paulsen, M. J.; Eskandari, A.; Hironaka, C. E.; Thakore, A. D.; Wang, H.; Yu, A. C.; Chan, D.; Appel, E. A.; Woo, Y. J. A Biocompatible Therapeutic Catheter-Deliverable Hydrogel for In Situ Tissue Engineering. Adv. Healthcare Mater. 2019, 8, 1801147.

(18) Purcell, B. P.; Lobb, D.; Charati, M. B.; Dorsey, S. M.; Wade, R. J.; Zellars, K. N.; Doviak, H.; Pettaway, S.; Logdon, C. B.; Shuman, J. A.; Freels, P. D.; Gorman, J. H.; Gorman, R. C.; Spinale, F. G.; Burdick, J. A. Injectable and Bioresponsive Hydrogels for On-Demand Matrix Metalloproteinase Inhibition. Nat. Mater. 2014, 13, 653-661.

(19) Yesilyurt, V.; Webber, M. J.; Appel, E. A.; Godwin, C.; Langer, R.; Anderson, D. G. Injectable Self-Healing Glucose-Responsive Hydrogels with $\mathrm{PH}-$ Regulated Mechanical Properties. Adv. Mater. 2016, 28, 86-91.

(20) Marco-Dufort, B.; Tibbitt, M. W. Design of Moldable Hydrogels for Biomedical Applications Using Dynamic Covalent Boronic Esters. Mater. Today Chem. 2019, 12, 16-33.

(21) Yu, J.; Wang, J.; Zhang, Y.; Chen, G.; Mao, W.; Ye, Y.; Kahkoska, A. R.; Buse, J. B.; Langer, R.; Gu, Z. Glucose-Responsive Insulin Patch for the Regulation of Blood Glucose in Mice and Minipigs. Nat. Biomed. Eng. 2020, 4, 499-506.

(22) Appel, E. A.; Forster, R. A.; Rowland, M. J.; Scherman, O. A. The Control of Cargo Release from Physically Crosslinked Hydrogels by Crosslink Dynamics. Biomaterials 2014, 35, 9897-9903.

(23) Brooks, W. L. A.; Deng, C. C.; Sumerlin, B. S. StructureReactivity Relationships in Boronic Acid-Diol Complexation. ACS Omega 2018, 3, 17863-17870.

(24) Springsteen, G.; Wang, B. A Detailed Examination of Boronic Acid-Diol Complexation. Tetrahedron 2002, 58, 5291-5300.

(25) Marco-Dufort, B.; Iten, R.; Tibbitt, M. W. Linking Molecular Behavior to Macroscopic Properties in Ideal Dynamic Covalent Networks. J. Am. Chem. Soc. 2020, DOI: 10.1021/jacs.0c06192.

(26) Tang, S.; Ma, H.; Tu, H. C.; Wang, H. R.; Lin, P. C.; Anseth, K. S. Adaptable Fast Relaxing Boronate-Based Hydrogels for Probing Cell-Matrix Interactions. Adv. Sci. 2018, 5, 1800638.

(27) Parada, G. A.; Zhao, X. Ideal Reversible Polymer Networks. Soft Matter 2018, 14, 5186-5196. 
(28) Tibbitt, M. W.; Kloxin, A. M.; Anseth, K. S. Modeling Controlled Photodegradation in Optically Thick Hydrogels. J. Polym. Sci., Part A: Polym. Chem. 2013, 51, 1899-1911.

(29) Tibbitt, M. W.; Kloxin, A. M.; Sawicki, L. A.; Anseth, K. S. Mechanical Properties and Degradation of Chain and StepPolymerized Photodegradable Hydrogels. Macromolecules 2013, 46, 2785-2792.

(30) Rehmann, M. S.; Skeens, K. M.; Kharkar, P. M.; Ford, E. M.; Maverakis, E.; Lee, K. H.; Kloxin, A. M. Tuning and Predicting Mesh Size and Protein Release from Step Growth Hydrogels. Biomacromolecules 2017, 18, 3131-3142.

(31) Lee, P. I. Diffusional Release of a Solute from a Polymeric Matrix - Approximate Analytical Solutions. J. Membr. Sci. 1980, 7, 255-275.

(32) Shen, W.; Zhang, K.; Kornfield, J. A.; Tirrell, D. A. Tuning the Erosion Rate of Artificial Protein Hydrogels through Control of Network Topology. Nat. Mater. 2006, 5, 153-158.

(33) Tang, S.; Wang, M.; Olsen, B. D. Anomalous Self-Diffusion and Sticky Rouse Dynamics in Associative Protein Hydrogels. J. Am. Chem. Soc. 2015, 137, 3946-3957.

(34) Tang, S.; Olsen, B. D. Relaxation Processes in Supramolecular Metallogels Based on Histidine-Nickel Coordination Bonds. Macromolecules 2016, 49, 9163-9175.

(35) Huang, X. Equilibrium Competition Binding Assay: Inhibition Mechanism from a Single Dose Response. J. Theor. Biol. 2003, 225, 369-376.

(36) Macosko, C. W.; Miller, D. R. A New Derivation of Average Molecular Weights of Nonlinear Polymers. Macromolecules 1976, 9, 199-206.

(37) Miller, D. R.; Macosko, C. W. A New Derivation of Post Gel Properties of Network Polymers. Macromolecules 1976, 9, 206-211.

(38) Stockmayer, W. H. Theory of Molecular Size Distribution and Gel Formation in Branched-Chain Polymers. J. Chem. Phys. 1943, 11, $45-55$.

(39) Grindy, S. C.; Learsch, R.; Mozhdehi, D.; Cheng, J.; Barrett, D. G.; Guan, Z.; Messersmith, P. B.; Holten-Andersen, N. Control of Hierarchical Polymer Mechanics with Bioinspired Metal-Coordination Dynamics. Nat. Mater. 2015, 14, 1210-1216.

(40) Kloxin, C. J.; Bowman, C. N. Covalent Adaptable Networks: Smart, Reconfigurable and Responsive Network Systems. Chem. Soc. Rev. 2013, 42, 7161-7173.

(41) Leibler, L.; Rubinstein, M.; Colby, R. H. Dynamics of Reversible Networks. Macromolecules 1991, 24, 4701-4707.

(42) Matsumoto, A.; Ishii, T.; Nishida, J.; Matsumoto, H.; Kataoka, K.; Miyahara, Y. A. Synthetic Approach toward a Self-Regulated Insulin Delivery System. Angew. Chem., Int. Ed. 2012, 51, 2124-2128.

(43) Angyal, S. J. The Composition of Reducing Sugars in Solution: Current Aspects. Adv. Carbohydr. Chem. Biochem. 1991, 49, 19-35.

(44) Hansen, M. M.; Jolly, R. A.; Linder, R. J. Boronic Acids and Derivatives - Probing the Structure-Activity Relationships for Mutagenicity. Org. Process Res. Dev. 2015, 19, 1507-1516. 